\title{
MALE MATE CHOICE IN A POLYMORPHIC DAMSELFLY NEHALENNIA IRENE (HAGEN)
}

by

Jennette N Fox

A thesis submitted to the Faculty of Graduate and Postdoctoral Affairs in partial fulfilment of the requirements for the degree of

Master of Science

in

Biology

Carleton University

Ottawa, Ontario

(C) 2013, Jennette N Fox 


\begin{abstract}
Male mate choice is a fundamental part of sexual selection. Here I contributed to the work on mate recognition by presenting conspecifics and heterospecifics to Nehalennia irene and Nehalennia gracilis to quantify their ability to recognize mates. I evaluated if inexperienced $N$. irene (sampled from an allopatric population where $N$. gracilis does not occur) show less discrimination between phenotypes than experienced males (sampled from a sympatric population where $N$. irene and $N$.gracilis co-occur). I performed high quality scans and colour analysis on thoraxes of all phenotypes to ascertain differences in colour between sites. I measured individual and population level mate preferences to evaluate the current hypotheses explaining sex limited polymorphism in odonates. Results taken together show that both species have difficulty in discriminating between phenotypes and that inexperienced and experienced males react in the same manner to potential mates. Colour analysis indicated there are differences in thorax colour between males, and between gynomorphs and other phenotypes but not between locations. Individual males showed no preferences for a specific morph inconsistent with hypotheses.
\end{abstract}




\section{Acknowledgements}

I would first like to thank my thesis supervisors Drs. Tom Sherratt and Christopher Hassall for their ongoing support, understanding and assistance. I benefited greatly from their expert guidance and greatly appreciate the hours of explanation and review they put into this thesis.

I would like to extend a special thanks to Dr. Mark Forbes for letting me become an honorary member of his lab and participate in lab meetings, and for his words of encouragement and thought provoking questions. I would also like to extend many thanks to my examining committee: Dr. Jessica Forrest, Dr. Jeff Dawson and Dr. Howard Rundle for their time and support. Additionally I would like to thank Dr. Stefan Van Dongen for his statistical analysis.

I owe my entire thesis to the help of my field crew: Dr. Christopher Hassall, Dr. Arne Iserbyt, Minnie Despas and my little dog Silken. Without their endless hours of toil in the sun, with biting bugs and leeches, knee deep in water and mud, snakes and the occasional poison ivy I would not have the copious amount of data that made my thesis worthwhile. I am very grateful for their assistance with my field work. I would also like to thank Queen's University Biological Station for letting my work and collect on their property.

I would like to acknowledge my officemates in the Sherratt and Gorelick labs for their caring and friendship: Richard Webster, Kevin Abbott, Thomas Hossie, Heather Penney, Dani Fraser, Sanoji Wijenayake and Lyndsay Derraugh. I would also like to acknowledge the support of my friends and family that helped me through the years. 


\section{Table of Contents}

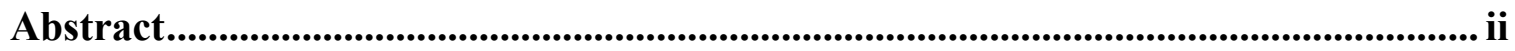

Acknowledgements ..........................................................................................................ii

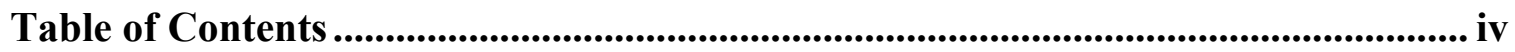

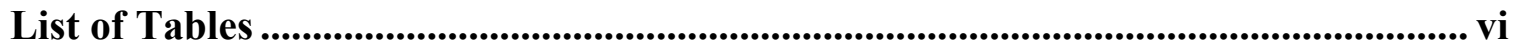

List of Figures...................................................................................................................................... viii

List of Appendices......................................................................................................................... xi

1 Chapter: Introduction ..................................................................................................... 12

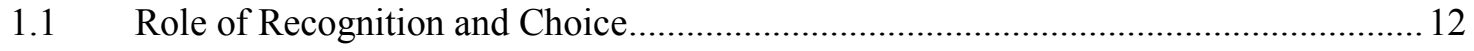

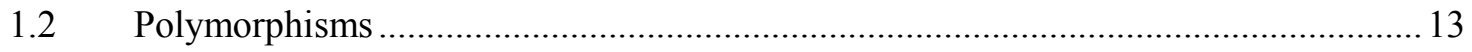

$1.3 \quad$ Visual (Colour) Polymorphism ………………………………………………..... 14

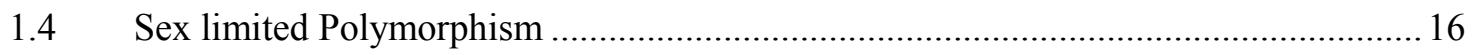

1.5 Sexual Selection and Male Mate Choice..................................................................... 17

1.6 Male Mate Choice in Odonata............................................................................ 18

1.7 Polymorphism in Odonata _.................................................................................... 19

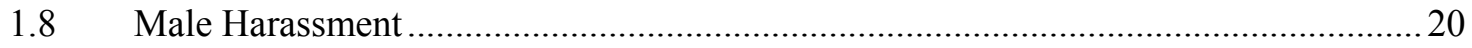

1.9 Reproductive Interference and Character Displacement .............................................23

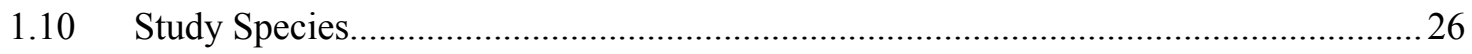

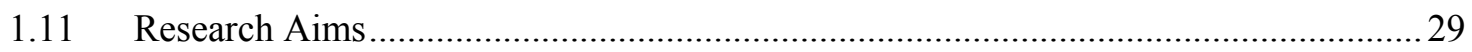

\section{Chapter: Male mate choice and reproductive interference in two sympatric}

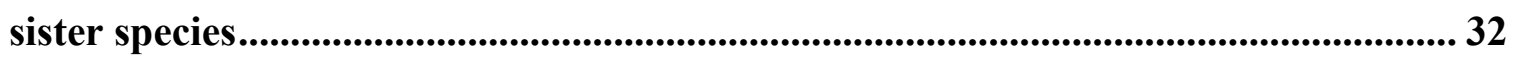

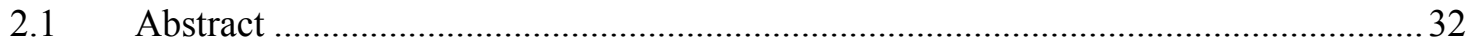

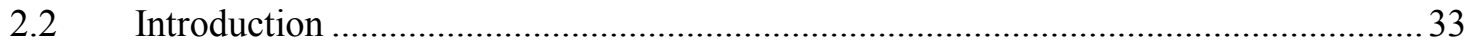

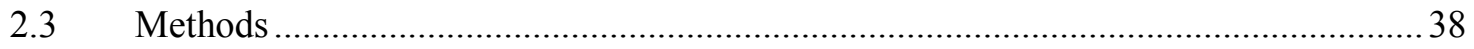

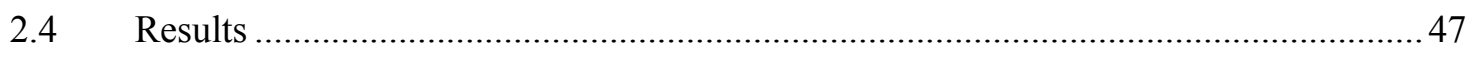


3 Chapter: The contributions of male mate choice to the maintenance of female polymorphisms ............................................................................................................................ 64

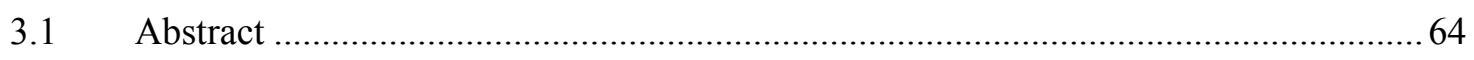

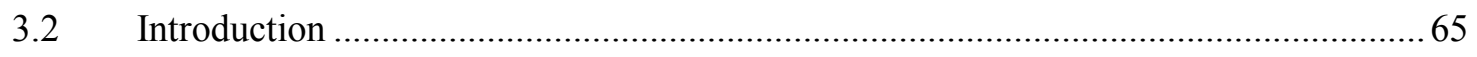

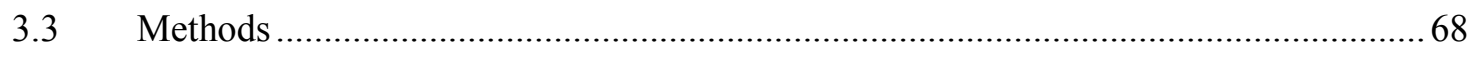

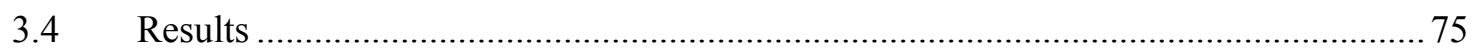

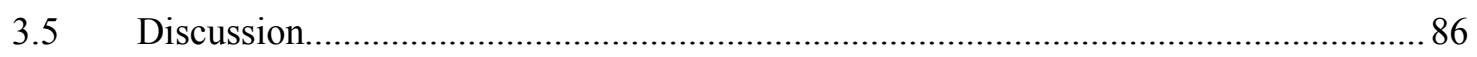

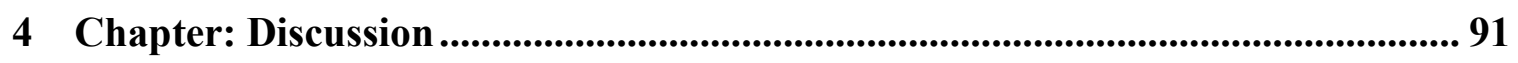

Appendices...................................................................................................................... 96

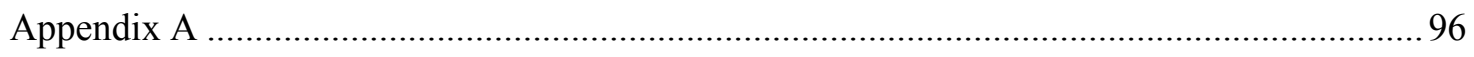

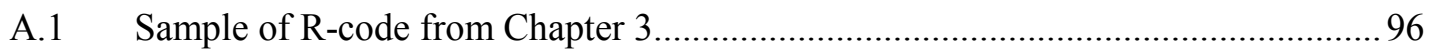

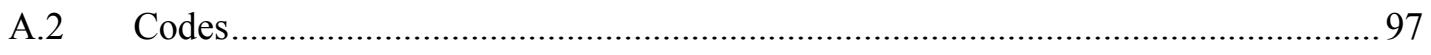

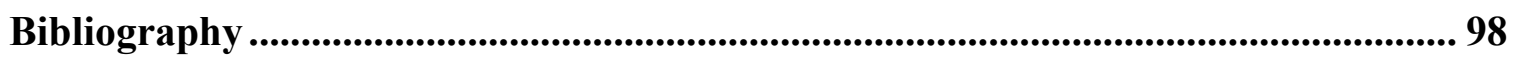




\section{List of Tables}

Table 1-1. Summary of signal detection decision making. A 'false alarm' results in the lost time and energy due to an unsuccessful mating attempt without reproductive output. A 'miss' results is the loss of a mating opportunity with a reproductively active partner. Correct decisions result in the benefit of saved time and energy. 25

Table 2-1. Summary of sample sizes for models and response males. Samples from 2010 are from the present study. Samples from 2004 are from Van Gossum et al. (2007)....... 43 Table 2-2. Pearson correlation (R) between environmental variables (Tmean, Tmax, precipitation) and male activity (mean number of tandem attempts) 55

Table 2-3. Summary of pair wise comparisons of thorax colour using MANOVA. Bonferroni correction requires a P-value of 0.005 for significance. Significant comparisons are in bold and marked with an '*'

Table 3-1. Illustration of one block (all six possible combinations of presentation order) of the design for testing the responsiveness of a male to all three morphs. ( $\mathrm{M}=$ male, $\mathrm{A}=$ andromorph, $\mathrm{G}=$ gynomorph; numbers refer to individuals)

Table 3-2. Summary of Variables included in modelling in R. For a complete definition of response male behaviour see 'sexual behaviour' in Chapter 2-3 Methods section...... 74 Table 3-3. Mean number of tandem attempts ( \pm SE) on andromorphs (A), gynomorphs (G) and males (M) over presentation order for male $N$. irene. All models experience a decrease in sexual activity at the same rate.

Table 3-4. Summary table of modelling. Greater numbers for evidence ratio indicates more support for the model. Location, order, model type, model type status, abdomen curl and block seem to be predictors of sexual behaviour by males. Appendix A includes 


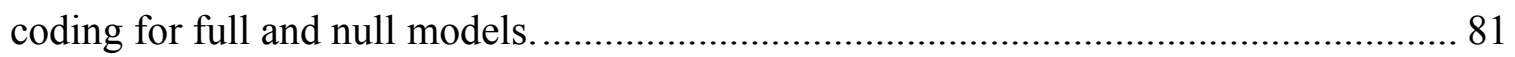




\section{List of Figures}

Figure 1-1. Examples of polymorphisms in a. male Mnais costalis where orange males are territorial and clear winged males are sneakers (photos $\mathbb{C}$ Yas Morioka), b. dorsal patterns on female tropical mainland anoles (photos (C) Ryan Carlsbeek) and c. polymorphisms in three spine stickleback based on habitat and sympatry (photos $\mathbb{C}$ Jeffrey S. McKinnon)

Figure 1-2. Model of signal detection theory. The red normal distribution curve is the probability density for male traits while the blue normal distribution curve is the probability density for female traits (Figure kindly supplied by K.A. Abbott). 22

Figure 1-3. a. Distribution map and colour illustration of $N$. irene male, andromorph and gynomorph and $\mathrm{b}$. distribution map and colour illustration of $N$. gracilis male and female (Lam 2004, Celestino 2006). 28

Figure 2-1. An example of a 2400 dpi scan of the left thorax and three 20 by 20 pixel areas selected for analysis with ImageJ. Scan is of a N. gracilis male from Herbert's Bog.

Figure 2-2. Comparison of the mean rate of tandem attempts (mean $\pm 1 \mathrm{SE}$ ) by male $N$. irene $(\mathrm{n}=19,16)$ and $N$. gracilis $(\mathrm{n}=19,14)$ on $N$. irene gynomorphs at Herbert's Bog. $\left(\mathrm{U}_{\text {irene }}=108, \mathrm{p}>0.05, \mathrm{df}=19,16 ; \mathrm{U}_{\text {gracilis }}=122, \mathrm{p}>0.05, \mathrm{df}=19,14\right)$. Previous study data (white) was collected in 2004 by Van Gossum et al. 2007 (Field Study 2). Present study data (Field Study 1) was collected in 2010 (grey).

Figure 2-3. a. The mean number of tandem attempts by $N$. irene response males (mean $\pm 1 \mathrm{SE}$ ) on each morph at a sympatric site. b. The mean number of tandem attempts by $N$. gracilis response males $( \pm \mathrm{SE})$ on each morph at a sympatric site. $\mathrm{F}=$ female, $\mathrm{M}=$ male, 
$\mathrm{A}=$ andromorph, $\mathrm{G}=$ gynomorph. ${ }^{1}=$ data obtained by Van Gossum et al. 2007 . Letters indicate non-statistically significant pairwise comparisons.......................................... 50

Figure 2-4. a. Comparison of mean number of tandem attempts by $N$. irene males (mean $\pm 1 \mathrm{SE}$ ) and $\mathrm{b}$. Comparison of proportion of total tandem attempts by $N$. irene males between allopatric and sympatric sites. White bars are allopatric sites, grey bars are sympatric sites. a. $N$. irene gynomorphs experience significantly different rates of attack between sites (Mann Whitney $\mathrm{U}=66.5, \mathrm{p}<0.05, \mathrm{df}=16,19$ ) marked with '*' 53

Figure 2-5. PCA analysis of colour of $N$. gracilis males and females and $N$. irene males, andromorphs and gynomorphs. Convex hulls show overlap between phenotypes. 58

Figure 3-1. Mean number of tandem attempts (mean \pm SE) over time (presentation order) for male $N$. irene for all models. Male response with the first presentation is consistent with previous findings. However, male response significantly decreases with multiple

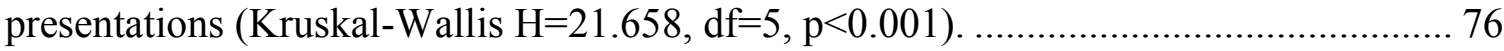
Figure 3-2. Comparison of population level preference for $\mathrm{A}=$ andromorphs, $\mathrm{G}=$ gynomorphs and $\mathrm{M}=$ male models by $N$. irene males at Alexandria (Black) and LeRoi Marsh (Grey). No differences in preference were found between location (KruskalWallis $\mathrm{H}=3.58, \mathrm{df}=5, \mathrm{p}=0.61$ ) or model (Alexandria: $\mathrm{H}=3.11$, $\mathrm{df}=2, \mathrm{p}=0.21$ : LeRoi: $\mathrm{H}=0.21, \mathrm{df}=2, \mathrm{p}=0.90)$ 79

Figure 3-3. Response male sexual behaviour (average number of tandem attempts) between models caught in copula $(\mathrm{n}=3$ ), individually (Single, $\mathrm{n}=50$ ) or in a tandem $(\mathrm{n}=62)$ with another individual. 83

Figure 3-4. Comparison of proportion of abdomen curls (or not) for andromorphs (A), gynomorphs $(\mathrm{G})$ and males $(\mathrm{M})( \pm 95 \% \mathrm{CI})$ out of all recorded trials $(\mathrm{n}=244)$. Abdomen 
curls were recorded in 52 (out of 244) presentations. Equal numbers of abdomen curls were recorded for all 3 morphs. 


\section{List of Appendices}

Appendix A............................................................ 96

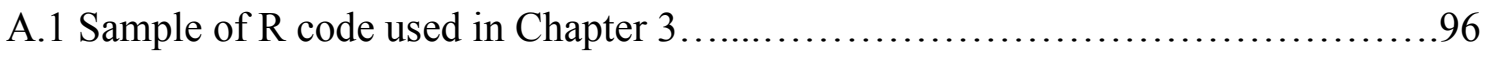

A.2 Codes.................................................................... 97 


\section{Chapter: Introduction}

\subsection{Role of Recognition and Choice}

A common requirement of most organisms is that they need to make decisions. To make a decision based on a response to an object an organism must typically go through a process of detection, recognition and choice. In this process, nearly all reasoning and decision making take place in the presence of some type of uncertainty (Heeger 1997). When the objects of choice are living, the nature of this uncertainty provides an opportunity for deceit and the potential for advantage over another. For example, prey can mimic unpalatable species, as in hoverflies (Diptera: Syrphidae) which are Batesian mimics of stinging wasps to avoid predation (Dittrich et al. 1993, Penney et al. 2012).

This uncertainty also exists with the recognition and identification of mates. Both male and female seek to maximize their reproductive output with the production of successful offspring. However differences in optimal reproductive schedules can create a conflict of interest within and between the sexes. In order to maximize individual output around this conflict of interest, a mate can employ a variety of strategies to use uncertainty to their benefit. For example, sneaker males are a common mating strategy where males deceive other males by appearing as females in order to avoid aggression (Sinervo and Lively 1996). Males can employ ‘dishonest' signals of their fitness in order to acquire mates (Johnstone and Grafen 1993). Additionally, females that experience costs due to excessive male harassment can become functional male mimics to avoid said harassment (Arnqvist and Rowe 2005). In these cases, polymorphisms may develop due to the frequency-dependent payoffs from different mating strategies within the same species. These multiple morphs offer different signals of recognition for mate choices. 


\subsection{Polymorphisms}

Polymorphism occurs when there are two or more phenotypically dissimilar morphs in a population that cannot be explained by the reoccurrence of a mutation (occurs in greater than $1 \%$ of the population) (Ford 1957). Although polymorphisms can be a temporary stage on the path to speciation, polymorphisms become permanent (or balanced) in populations when there is an equal average fitness at equilibrium between the morphs (Smith 1989). Several mechanisms create and balance polymorphisms in a species. Polymorphisms can develop under frequency dependent selection through predator prey or mate choice interactions. Frequency dependent apostatic selection, when predators concentrate on morphs they are familiar with, can balance selection between morphs. A classic example is the selection of 'prey' baits in wild garden birds (Allen et al. 1998). When densities of baits are low the commonest colour of baits is eaten disproportionally more than other bait colours. However this switches to anti-aposematic selection when baits are at high density (Allen et al. 1998). Male guppies (Poecilia reticulata) are under extreme negative frequency dependent selection for mating success by female guppies that prefer novel and unusual morphs over more commonly coloured males (Hampton et al. 2009). In addition, polymorphisms can evolve through heterosis, where heterozygotes have greater fitness of over homozygotes. In plants heterosis, or hybrid vigour is linked to higher agronomic performance (Swanson-Wagner et al. 2006, Baranwal et al. 2012, Meyer et al. 2012). Polymorphisms can be mediated by a combination of environmental and genetic cues. In addition polymorphisms can develop when there are differences in fitness over space and time (Smith 1989). 


\subsection{Visual (Colour) Polymorphism}

Understanding how evolutionary processes maintain variation in a population is an important goal of evolutionary biology, and colour polymorphisms are a useful tool to reach this goal. They provide visible phenotypic variation that is easily measured as an indicator of underlying genetic variation (Calsbeek and Cox 2012). Most colour polymorphisms are based at a single locus, or a group of tightly limited loci. Examples of colour polymorphism are common in many taxa including fish (Dorn et al. 2011), amphibians (Bonansea and Vaira 2012), reptiles (Paemelaere et al. 2011), birds (Pryke et al. 2012), mammals (Guridi et al. 2011) and insects (Berniker and Weirauch 2012) (Figure 1-1).

Several polymorphic species have become model systems to study the processes of evolution that shape and maintain genetic and phenotypic variation in nature. A classic model system that illustrates visual polymorphism and evolution in progress is that of industrial melanism in the peppered moth Biston betularia (Kettlewell 1955). After the industrial revolution, pollution caused trees in urban areas to have darkened tree bark, on which melanic forms of the peppered moth were difficult to detect by visual predators while white forms were easily seen and eaten. However, white forms of the moth remained common in unpolluted rural areas. Nowadays, with cleaner industries, tree bark has lightened and white forms are once again common in urban areas (Majerus 2009). 


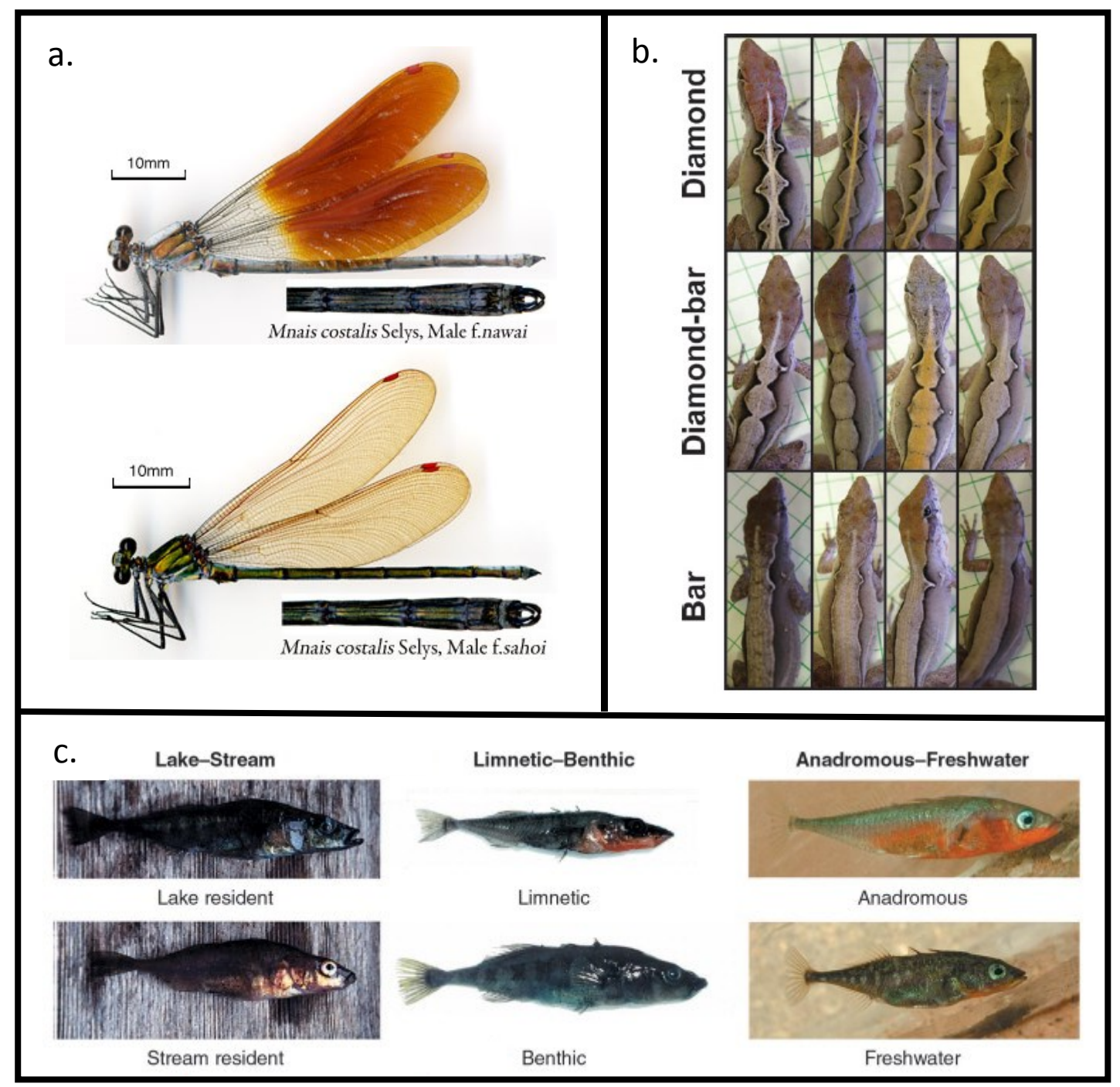

Figure 1-1. Examples of polymorphisms in a. male Mnais costalis where orange males are territorial and clear winged males are sneakers (photos $(\mathcal{C}$ Yas Morioka), b. dorsal patterns on female tropical mainland anoles (photos $($ ) Ryan Carlsbeek) and c. polymorphisms in three spine stickleback based on habitat and sympatry (photos $@$ Jeffrey S. McKinnon). 


\subsection{Sex limited Polymorphism}

Phenotypic differences between the sexes are known as sexual dimorphism, however phenotypic variation within one sex is known as sex limited polymorphism. Sex limited polymorphisms can often be explained by sexual selection. Male limited polymorphisms are usually thought to arise due to competition between males and result in alternative mating strategies by each morph. For example in the side blotched lizard, Uta stansburiana, both males and females are polymorphic. In males there are three colour morphs that are correlated with alternative reproductive strategies to acquire mates, and a rare strategy is advantageous over a common one. Yellow males are sneakers in that they mimic the colouration and behaviours of females in order to acquire mates and defeat ultra-dominant orange males. In turn, yellow males are defeated by blue mate guarding males that are not fooled by the sneaker strategy. Finally, orange males will defeat blue males in aggressive displays to acquire more mates (Sinervo and Lively 1996).

Female limited polymorphisms are different from male limited polymorphisms. In females there are several adaptive and non-adaptive mechanisms that contribute to the development of sex-limited female polymorphism. In the Common Mormon butterfly, Papilio polytes, two morphs are Batesian mimics of different unpalatable models (Pachliopta aristolochiae and Pachliopta hector) to reduce predation, while the other morph is similar to the male (Yamauchi 1993, Uesugi 1996). Females of the side blotched lizard, Uta stansburiana, utilize alternative reproductive strategies with tradeoffs. Orange throated females are r-strategists in that they produce numerous small eggs while yellow throated females are K-strategists in that they produce fewer larger eggs (Sinervo et al. 2000). Female predatory diving beetles avoid male harassment which 
involves being held under water, suffocation and the possibility of death by having morphs with different surfaces of their backs. These different surfaces impair the males ability to hold on and reduce the detrimental effects of their harassment (Bergsten et al. 2001). In most cases female polymorphism seems to have arisen in these species as a consequence of sexual selection (Andres et al. 2000). Thus, it has been widely hypothesized that female polymorphism has been generated as a response to male mate choice.

\subsection{Sexual Selection and Male Mate Choice}

Studies of sexual selection have usually focused on female mate choice (Jennions and Petrie 1997, Candolin et al. 2007) however, more and more studies are addressing male mate choice. In syngnathid fishes (pipefish and seahorse) females are under sexual selection by males in colour and size in exchange for parental investment by the male (Vincent et al. 1992). Dance fly (Diptera: Empididae) males choose young, large, reproductively available females in exchange for nuptial gifts (Svensson and Petersson 1987, Svensson 1997). Male mate choice is now known to occur in many groups including amphibians (Arntzen 1999), birds (Hill 1993, Saether et al. 2001), fish (Wong 2004), mammals (Szykman et al. 2001) and is widespread in arthropods including arachnids (Bel-Venner et al. 2008), crustaceans (Reading and Backwell 2007) and insects (Bonduriansky 2001), including parasitoids (Martel et al. 2008). Male choice seems likely to evolve when males experience a high cost of reproduction and/or a large variation in female quality (Kvarnemo and Simmons 1999, Kokko and Monaghan 2001, Kokko et al. 2002, Clutton-Brock 2007, Guevara-Fiore et al. 2010). However, male mate choice can also evolve when males are liable to confuse conspecific males with females 
or heterospecifics (Sherratt, 2013).

\subsection{Male Mate Choice in Odonata}

In Odonata (damselflies and dragonflies), male mate choice has been shown to occur, and has been relatively well-studied in the context of the evolution of female-limited polymorphisms (Robertson 1985, Cordero Rivera 1998, Miller and Fincke 1999, Van Gossum et al. 2001b, Fincke 2004, Van Gossum et al. 2007, Iserbyt and Van Gossum 2011). Numerous studies have shown that mate-searching males discriminate among phenotypes, rather than randomly approaching individuals (Miller and Fincke 1999, Van Gossum et al. 2001b, Miller and Fincke 2004, Rivera and Sanchez-Guillen 2007, Hammers and Van Gossum 2008, Takahashi and Watanabe 2009, Ting 2009, Van Gossum et al. 2011). If there are differences in quality between those phenotypes male should choose phenotypes that signal higher quality. For example in the event of differences in fecundity between the morphs, males should preferentially choose the more highly fecund morph (Servedio and Lande 2006). In insects, several studies have found that male mate choice is often observed when there is large female mate quality variance, or differences in fecundity (Gwynne 1981, Bonduriansky 2001, Nakahashi 2008). In damselflies, fecundity as measured by egg load has been found to be significantly different between female morphs (Bots et al. 2009c, Takahashi and Watanabe 2010b, Iserbyt et al. 2013). This suggests that there may be a driver in odonates, similar to other species, for male mate choice.

More general features of the damselfly life-history also lend themselves to active selection for male mate choice. If the copulatory process is energetically expensive, or brings risk to the male, then it seems reasonable that males should be choosy as to who 
they decide to copulate with, provided female quality also varies. In odonates with mate guarding, copulation can take from 15 minutes to several hours depending on species and female receptivity (Andres et al. 2000). During this time, males are unavailable to pursue other females and are unable to eat, lowering their energy reserves (Reading and Backwell 2007). In addition, mating pairs are at greater risk of predation during tandem formation (Dijkstra et al. 2001). In these cases, it may be important for males to engage in mate choice and thereby maximize their reproductive efficiency.

\subsection{Polymorphism in Odonata}

In odonates both male and female polymorphisms occur. Male polymorphisms usually occur in territorial damselflies where males compete for mates. In calopterygids such as Mnais costalis, males are polymorphic for wing colour which correlates with mating strategy (Figure 1-1a). Orange winged males are territorial while clear winged males employ a sneaker strategy to obtain mates. Males recognize each other's mating strategy by wing coloration. Although clear winged males will not attack territorial orange males they will attack other clear winged males with the same mating strategy (Watanabe and Taguchi 1990, Hooper et al. 2006).

Female polymorphisms are common, particularly in Coenagrionidae, with the presence of two or more distinct female morphs (Ford 1957, Forbes 1991b). Usually there is one andromorph (also referred to in the literature as "androchrome"), phenotypically similar to the male and at least one gynomorph (also referred to in the literature as "gynochrome" or "heterochrome") that is dissimilar to the male. These morphs can differ in morphology and/or behaviour. For some species, andromorphs are smaller and produce fewer eggs than gynomorphs (Iserbyt et al. 2013 but see Lejeunesse 
and Forbes 2003, Takahashi and Wantanabe 2010b), have differences in wing morphology (Bots et al. 2009a, McTavish et al. 2012), or differences in immune function and parasite resistance (Joop et al. 2006a, Sanchez-Guillen et al. 2013). In addition, there are many behavioural differences between these females. Andromorphs seem to mimic male behaviours by spending more time at the shoreline of ponds (Forbes et al. 1997), flying shorter distances, perching and spending more time in the open similar to males, and displaying aggressive charges when resistant to mating (Van Gossum et al. 2001a, Sirot et al. 2003). It has been also suggested that these morphs differ in their degree of resistance toward male mating attempts and total number of matings (Gosden and Svensson 2007, 2009).

\subsection{Male Harassment}

In damselflies, theory predicts a difference in optimal mating rates between males and females. Females typically require sperm from only one male to fertilize all their eggs (Cordero 1990, Fincke 1997), and so benefit from moderate mating rates (Arnqvist and Rowe 2005). By contrast, males increase their lifetime mating success with a high mating rate (Iserbyt and Van Gossum 2009). Thus, there is a conflict of interest between males and females in terms of desirable mating rates, and frequently a high level of male harassment (Rivera and Andres 2002, Hardling and Bergsten 2006, Svensson et al. 2009). This male harassment has a negative impact on the fitness of damselfly females (Ubukata 1984, Waage 1987, Arnqvist and Rowe 2005, Svensson et al. 2009) and females are expected to resist persistent males and superfluous matings (Rivera and Andrés 2002).

Currently there are two main theories explaining the maintenance of female polymorphism in damselflies. One theory for the maintenance of female-limited 
polymorphisms is the male-mimic hypothesis (MM) which states that male harassment has led one female morph (andromorph) to become a mimic of the male and thereby gain a degree of protection from harassment (Robertson 1985). This can be quantitatively modelled using signal detection theory. For each morph of a species there is a normal distribution of perceived signals (Figure 1-2). These distributions overlap for some traits between morphs. This creates an area across which there is either correct identification or misidentification. For example, when a male makes a decision about a potential mate they compare the signal they are receiving to their threshold (Figure 1-2). If an andromorph is in the overlap of the distribution for males and below the threshold, this creates a chance of 'misses' by the decision making male (Figure 1-2). However, like classical Batesian mimicry, the MM hypothesis would suggest that any advantage is frequency-dependent, requiring rarity of andromorphs (mimics) relative to males (models). When andromorphs are common it will pay males to more carefully differentiate andromorphs from males, so the advantage of mimicry is reduced. Indeed, at high frequencies andromorphs may be more harassed than gynomorphs on account of their higher conspicuousness and high attack thresholds of males (Sherratt 2001, Kunte 2009). 


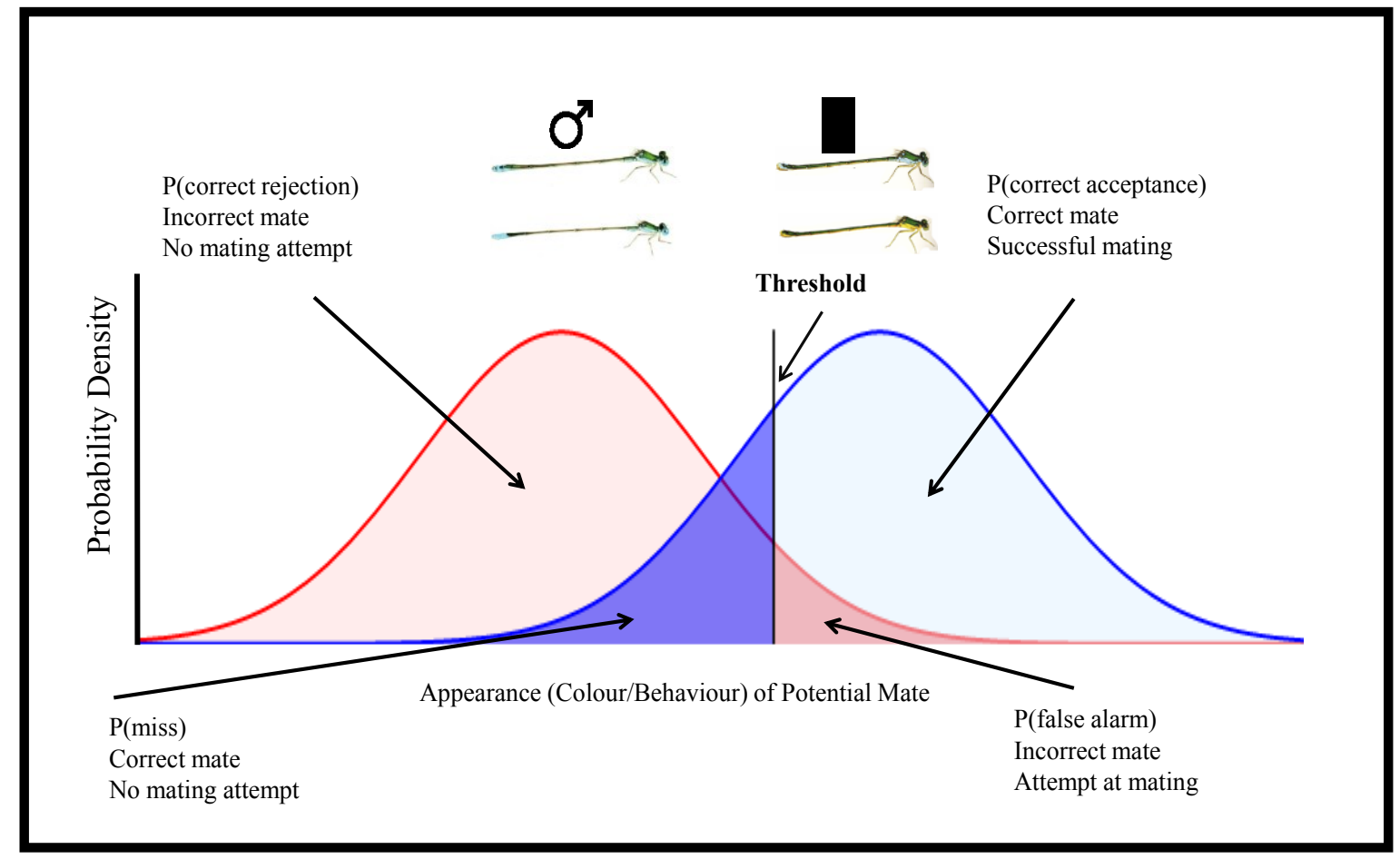

Figure 1-2. Model of signal detection theory. The red normal distribution curve is the probability density for male traits while the blue normal distribution curve is the probability density for female traits (Figure kindly supplied by K.A. Abbott). 
An alternative hypothesis for male mate choice is the learned mate recognition hypothesis (LMR). This postulates that males choose between female morphs in a frequency-dependent manner, simply based on previous successful mating experience (Miller and Fincke 1999). In this case the rarer morph has an advantage over the common one, reducing its' harassment by males. Here the form of frequencydependence in male mate choice rests not on the ratio of andromorphs to males but on the ratio of andromorphs to gynomorphs. Studies have shown rather mixed evidence for both hypotheses (Van Gossum et al. 1999, Córdoba-Aguilar 2008).

The precise point of equilibrium, and even the maintenance of polymorphisms themselves can be influenced by natural rather than sexual selection. For example, the colour polymorphism in Megalagrion calliphya, has been found to arise as a consequence of an environmental gradient in levels of solar radiation (environmental heterogeneity). Red females may have superior antioxidant ability that may protect from UV damage at higher altitudes with increased sunlight, compared to green unprotected females. In some solar environments both females can co-occur (Cooper 2010).

\subsection{Reproductive Interference and Character Displacement}

During the reproductive process, sexual interactions between two similar co-occurring species can take place. This reproductive interference can produce hybrids, upset time and energy budgets, reduce reproductive success and is detrimental to one or both species (Sanchez-Guillen et al. 2005, Tynkkynen et al. 2008, Takahashi and Watanabe 2010a, Keranen et al. 2013). To reduce these costs, morphological or behavioural divergence ("reproductive character displacement") in one or both species can occur. In odonates, character displacement in male wing colouration has been shown to occur as a 
consequence of selection to reduce interspecific aggression (Waage 1975b, Tynkkynen et al. 2004, Kuitunen et al. 2011). It is hypothesized that in two similar species of odonates, where males make signal detection errors and harass heterospecifics (false alarms), that heterospecific females may experience reproductive interference (Table 1-1) (Van Gossum et al. 2007). In this case, character displacement to increase correct mate identification (and decrease incorrect identification) may evolve in the species that is incorrectly harassed, as it would result in fewer signal detection errors (false alarms) to the receiver and lower harassment rates to the signaller.

As Odonata are known to have extremely well developed vision (Briscoe and Chittka 2001) with the ability to see within the ultraviolet (UV) to red spectrum (Yang and Osorio 1991, Schultz et al. 2008, Bybee et al. 2012) it has been postulated that male mate recognition and choice is likely to be based on visual cues such as colour. Males have been shown to discriminate between females (Gorb 1998, Miller and Fincke 1999, Joop et al. 2006a, Van Gossum et al. 2011) and prey through use of colour (Walguarnery et al. 2009). In this case, the most likely avenue of character displacement is through changes in colour. Previous work has shown that abdominal and thorax colour and pattern are important cues for mate recognition in odonates (Miller and Fincke 1999, Van Gossum 2008, Van Gossum et al. 2011). Colour changes in these areas would be predicted to offer protection from reproductive interference. 
Table 1-1. Summary of signal detection decision making. A 'false alarm' results in the lost time and energy due to an unsuccessful mating attempt without reproductive output. A 'miss' results is the loss of a mating opportunity with a reproductively active partner. Correct decisions result in the benefit of saved time and energy.

\begin{tabular}{|l|l|l|}
\hline & Conspecific and Opposite Sex & Heterospecific or Same Sex \\
\hline Attempt Tandem & $\begin{array}{l}\text { Correct Decision } \\
\text { (Mating Attempt) }\end{array}$ & $\begin{array}{l}\text { Type I Error } \\
\text { (Unsuccessful Attempt } \\
\text { 'false alarm') }\end{array}$ \\
\hline Do not Attempt & $\begin{array}{l}\text { Type II Error } \\
\text { (Loss of Opportunity } \\
\text { 'miss') }\end{array}$ & $\begin{array}{l}\text { Correct Decision } \\
\text { (No Attempt) }\end{array}$ \\
\hline
\end{tabular}




\subsection{Study Species}

In order to study male mate choice I used the damselfly species Nehalennia irene. $N$. irene is a common, widespread damselfly that inhabits ponds and marshes across Canada and the US (Figure 1-3a). It has a blue-black male distinguished by two triangular patches on abdomen segments 9 and 10 (Figure 1-3a). N. irene has 2 female morphs, a blue-black female with two triangular patches on abdominal segments 9 and 10 called the andromorph (or androchrome), and a yellow-based female known as the gynomorph (or gynochrome or heterochrome) (see Figure 1-3a) (Lajeunesse and Forbes 2003, Lam 2004).

In addition to $N$. irene I used the congeneric damselfly, $N$. gracilis that lives sympatrically with $N$. irene to investigate reproductive interference and character displacement. $N$. gracilis has a more limited range than $N$. irene, specializing in bogs and fens of the east coast of the US and Canada (Figure 1-3b). N. gracilis has a blue black male with blue abdominal segments 8, 9 and 10 without triangles (Lam 2004). It is a monomorphic damselfly with one blue black female with black triangles on abdominal segments 9 and 10 and appears visually identical to $N$. irene males and andromorphs (Figure 1-3b).

In these species blue, black and yellow colours are the most common. Blue colouration is due to structural arrays of colour-producing spheres within epidermal pigment cells underlying the cuticle (Vernon et al. 1974, Charles and Robinson 1981, Prum et al. 2004). Yellow tones are not structural but are shown to be epidermal ommochrome pigments, specifically decarboxylated xanthommatin in oxidized form (Futahashi 2012). In insects, black tones are produced from the pigment melanin, which 
may be altered by environmental factors and nutrition (Nijhout 2010, Outomuro and Ocharan 2010). After death, these pigments are not maintained and odonates lose their colour (Abbott 2005).

Males spend time in the sedges at the shorelines of ponds waiting for females; while females spend most of their time away from shorelines in order to mature eggs and feed. Females return to the pond when they are reproductively mature and ready to mate. As this area around the pond is then male biased, the males engage in a 'scramble' competition for females. Once a pair have mated they remain in tandem at the oviposition sites until eggs are laid. In this way males guard their mate from other males. 


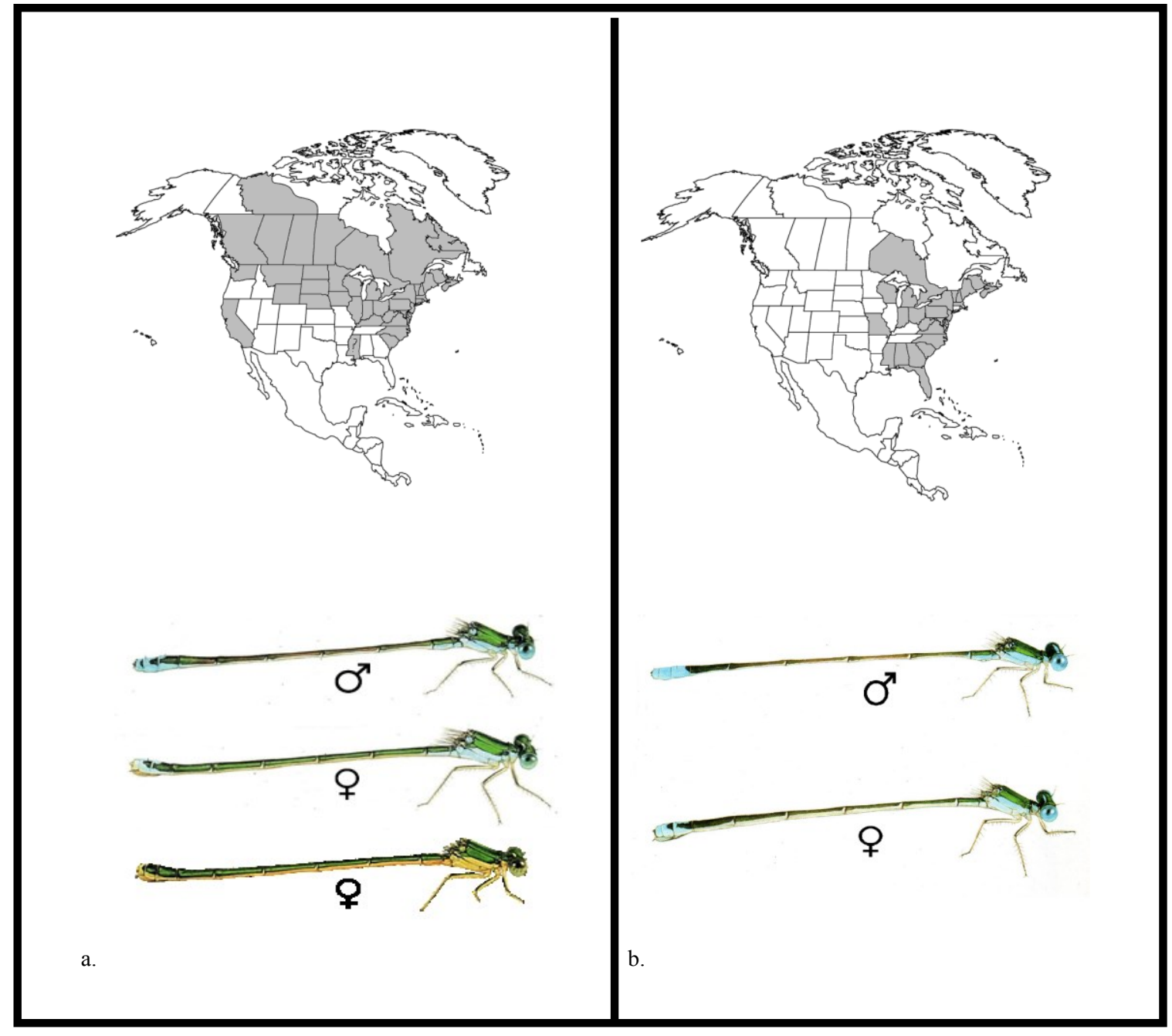

Figure 1-3. a. Distribution map and colour illustration of $N$. irene male, andromorph and gynomorph and b. distribution map and colour illustration of $N$. gracilis male and female (Lam 2004, Celestino 2006). 


\subsection{Research Aims}

We had several related objectives with my research. Previous work by Van Gossum et al. (2007) looked at male mate discrimination and reproductive interference between $N$. irene and N. gracilis at a sympatric location. They presented conspecific and heterospecific females to both $N$. irene and $N$. gracilis males to investigate mate choice for females and if reproductive interference is occurring. In Chapter 2 we aimed to add to their work by presenting the other $N$. irene and $N$. gracilis morphs to sympatric and allopatric $N$. irene and $N$. gracilis males. Analysis of male reactions to all phenotypes will allow us to quantify mate recognition in $N$. irene and $N$. gracilis. In addition, comparison of male sexual behaviour to possible mates between these sites will tell us about differences in choices between experienced and inexperienced males. This allowed us to have a complete picture of mate recognition and male mate choice in these two species. This is of value because much research has been conducted on mate preferences by odonate males for females but usually does not include preferences for all potential mates in the system. This also adds to the body of work on the role of mate recognition in character displacement and speciation (Fincke et al. 2007).

In addition, the work by Van Gossum et al. (2007) found possible reproductive interference between the two species leading to exclusion of $N$. gracilis. If reproductive interference is occurring and impacting $N$. gracilis, character displacement may also occur to reduce this interference in sympatric populations. We investigated character displacement of thorax colour in $N$. irene and $N$. gracilis by obtained high quality (2400 dpi) scans of freshly killed damselfly specimens at all sites and analysed thorax colour for red blue and green using the program ImageJ. Principle component analysis (PCA) of 
RGB colour were used to look for differences in thorax colour between $N$. gracilis males and females and $N$. irene males, gynomorphs and andromorphs. We used pairwise comparisons in multiple analysis of variance (MANOVA) with Bonferroni correction to identify statistical differences in thorax colour between phenotypes. This work not only allowed us to quantify how similar blue black morphs were to each other, and specifically $N$. irene andromorphs were to males, but to also test whether there were differences in thorax colour in $N$. irene males and gynomorphs between sympatric and allopatric sites. This is of value because greater differences in thorax colouration in sympatric sites could be the result of character displacement between $N$. irene and $N$. gracilis. Although research into reproductive character displacement is ongoing, there are few concrete examples (Schluter and McPhail 1992, Grant 1994).

There are two main hypotheses that explain the maintenance of colour polymorphism in odonates. In Chapter 3 we evaluated the LMR and MM hypotheses by comparing individual male mate choice to population level mate choice. This work was important because to date researchers have evaluated the preference of a population of males, without assessing how this population preference is composed. For example, if males on average attack gynomorphs on $60 \%$ of occasions, and andromorphs on $30 \%$ of occasions, do all males show the same responses or is this variation due to some males preferring gynomorphs and some males preferring andromorph? The LMR predicts the male population will be composed of specialists, with males preferring the most common morph. In any population some males will prefer andromorphs through earlier experiences with them, and other males will prefer gynomorphs. Conversely, the MM hypothesis predicts that males will be generalists choosing both female morphs based on 
recognition. However, until we can decompose population preference through repeated presentations of different morphs to the same individual then we have no way of evaluating the extent of inter-male variation in preference. Finally, the behaviour of the model offered may well have an influence on its attractiveness to males, so we sought to quantify the models behaviour (e.g. abdomen curling, wing flutter) when assessing male mate preference. 


\section{Chapter: Male mate discrimination and reproductive interference}

\subsection{Abstract}

Closely related species in sympatric populations will generally experience strong selection on males and females to discriminate appropriate mates amidst the noise. Without this discriminatory ability, one or both species could experience costs of interspecific interactions. Conveniently, the interactions themselves can lead to character displacement, morphological or behavioural changes in sympatric species to reduce their costs. We used two related species of odonates, Nehalennia irene and Nehalennia gracilis that co-occur to study male discriminatory ability and reproductive interference. On experimentally presenting male and female $N$. irene and $N$. gracilis live models to $N$. irene and $N$. gracilis males, $N$. irene males showed the ability to discriminate their gynomorph from all other models, while $N$. gracilis males did not distinguish their female from all other models. Since $N$. gracilis is locally rare, these results suggest that the cost of missed opportunities to mate is greater than the cost of false alarms and that $N$. gracilis females may be under pressure through reproductive interference by $N$. irene. Additionally, $N$. irene males showed no difference in discriminatory ability when comparing the preferences of $N$. irene between populations where $N$. gracilis was present and where it was absent (sympatry vs. allopatry). As odonates are known for their visual acuity and use of vision to find prey and mates, it was hypothesized that there could be character displacement of thorax colour between these species. We analysed high quality (2400 dpi) colour scans of thoraxes of all phenotypes for differences between sympatric and allopatric locations. Although interference seems to be occurring between $N$. irene and $N$. gracilis, our results do not indicate character displacement for visible colour. 
However, females could be using other alternative behavioural or morphological strategies to prevent reproductive interference.

\subsection{Introduction}

Reproductive interference between heterospecifics can be extremely costly as the outcomes might include the production of infertile hybrids, and/or detrimental effects to time and energy budgets of either sex in at least one of the species (Singer 1990, Parris 1999, 2001). Character displacement is a process by which costly interactions between two species cause them to diverge in morphology and/or behaviour (Grant 1994). In Calopteryx, character displacement of wing pigmentation in female C. aequabilis in sympatry with C. maculata has been observed (Waage 1975a, Mullen and Andres 2007). In addition, $C$. maculata males seem to have greater discrimination ability for their own females at sympatric sites (Waage 1975a). These species have no mechanical barriers to hybridization and spend time in territorial disputes, both motives for the evolution of character displacement when sympatric (Waage 1979, Mullen and Andres 2007). For females male harassment has been shown to lead to disruption of female time and energy budgets, injury, and possibly even death (Forbes 1991a, Van Gossum et al. 2005b, Takahashi and Watanabe 2010a). In the case of harassment by heterospecific males, females would experience these costs without any reproductive output. For males costs of reproductive inference is loss of time and energy, increased predation while in tandem with females and production of hybrids. In this instance we would expect to see differences in behaviour between sympatric and allopatric populations of related species experiencing reproductive interference by heterospecifics. 
Two species of closely related damselfly, Nehalennia irene and Nehalennia gracilis occur sympatrically and allopatrically and offer a potential model for looking at reproductive interference in odonates. Although $N$. irene and $N$. gracilis appear similar and co-occur, genetic studies have shown that they have a distinct evolutionary history in that they diverged after the last glacial age (Iserbyt 2010). Both species are New World species common to North America. $N$. irene is an abundant and widespread damselfly that is found in a wide range of small lentic habitats with a developed fen zone while $N$. gracilis is an east coast species that has a more specific habitat requirement of bogs and fens. Research has shown that when these species occur together $N$. irene tends to be at greater abundances, leading to the belief that $N$. irene may exclude $N$. gracilis from sites (Van Gossum et al. 2007). In this case $N$. gracilis would experience greater pressure for character displacement from reproductive interference with $N$. irene, since the likelihood of $N$. irene making mistakes is concomitantly lower.

$N$. irene and $N$. gracilis have similarly coloured and patterned females that closely resemble $N$. irene males. $N$. irene males have a blue-green thorax, a mostly black abdomen with abdominal segments 9 and 10 coloured blue and with a pair of black spots (Figure 1-3a). N. irene has two distinct female forms, a blue and black female (andromorph) visually identical to the male, and a less conspicuous yellow female (gynomorph) (Lam 2004). N. gracilis males are similar to N. irene males and andromorphs in that they have a blue thorax and mostly black abdomen, but they are distinct in that they lack the pair of black spots on abdominal segments 9 and 10. N. gracilis is monomorphic, with one female form that is visually identical to $N$. irene males and andromorphs, and that has the pair of black spots on abdominal segments 9 and 10 
(Figure 1-3b).

One explanation for the evolution and maintenance of polymorphic females in $N$. irene is the male mimicry hypothesis (Robertson 1985). This hypothesis states that andromorph females have evolved to be male mimics to lower the ability of males to recognize them as females, in turn lowering their rate of harassment and its detrimental effects (Robertson 1985, Takahashi and Watanabe 2010a). Successful mimicry is a frequency dependent effect based on being able to fool the signal-receiver (mate searching males) (Sherratt 2001). If mimics are common in a population relative to models, the signal-receiver has greater experience with them and is less likely to be deceived. Thus, the benefit of mimicry to $N$. irene andromorphs is based on the local frequencies of mimics and models.

In addition, males have to be able to detect their female (signal) from conspecific males and heterospecifics (noise). Responses to noise cost time, energy, possible missed opportunities of detecting a true mate (lack of encounters if occupied with non-mates), increased predation risk, and damage to the male due to harassment (Parker 1983, Mullen and Andres 2007). In sympatric locations, $N$. gracilis females would act as noise, increasing the difficulty of identification of $N$. irene andromorphs. In this case the noise generated by $N$. gracilis would be predicted to induce $N$. irene males to increase their discrimination ability for their own andromorph. N. gracilis males would experience the same noise by heterospecifics and also be under selection to increase their discrimination ability while $N$. gracilis females would be under selection to produce a clearer signal to the males.

On the other hand, if $N$. irene and $N$. gracilis have a low signal to noise ratio 
(many false alarms, Table 1-1) they have a low discrimination ability (threshold) and would attempt mating with a larger variation of mates. Because they are so willing to mate these males are unlikely to miss a conspecific female when they find one. This may be of benefit when females are rare, as in this system (Fincke 2004). Overall, the above list of losses for responding to false positives must cost less than the increase in male reproductive success by using this strategy.

This research includes two studies. Field study 1 was carried out in 2010 by myself and field crew. Field study 2 was previously published work by Van Gossum et al. (2007). In this study (Field Study 1) we set out to test male N. irene and N. gracilis males' discrimination ability for their own females out of all potential mates in a sympatric system. We presented $N$. irene gynomorphs and males and $N$. gracilis males (3 phenotypes) to $N$. irene and $N$. gracilis males at a sympatric site. We then combined this data with data collected previously at the same location. This previous work by Van Gossum et al. (2007) looked at male mate choice by $N$. irene and $N$. gracilis males solely between female types ( $N$. irene andromorphs and gynomorphs, $N$. gracilis female; Field Study 2). The combined data adds to their work by investigating male mate choice to the remaining potential mate types ( $N$. irene and $N$. gracilis males) at the same locations. With this information, we can look at male responses to all potential mates (all noise) and identify each male's ability to recognize their own conspecific females. In addition, we tested the difference in discrimination ability by $N$. irene with and without behavioural experience of $N$. gracilis. As $N$. gracilis is unknown in some years at my location, evolutionary experience in discrimination between these two species is unknown (Van Gossum et al. 2007). We presented $N$. irene males, gynomorphs and $N$. gracilis males to 
$N$. irene males at an allopatric site. By comparing the differences in male mate choice between sympatric and allopatric populations we can determine if ( $N$. irene) males can learn to distinguish their females from noise; and both males' non responsiveness rate to females.

Since at sympatric sites $N$. gracilis tend to be rare compared to $N$. irene they will encounter inappropriate mates at a high rate compared to successful encounters with mature, conspecific females; and will incur a higher cost in finding a conspecific female than $N$. irene males. It is expected then that $N$. gracilis males will exhibit much stronger selectivity when presented with potential mates, because the probability of any given potential mate being inappropriate for $N$. gracilis is concomitantly higher.

At a $N$. irene allopatric site, $N$. irene will have no experience with $N$. gracilis as a potential mate. Here, we expect to find that $N$. irene will be even less able to discriminate between heterospecifics and its conspecific female as at a sympatric location, increasing its rate of making attempts on unsuitable mates.

\section{Character Displacement of Colour}

In odonates, previous research has found that abdomen and thorax colour and pattern are important signals to males (Bick and Bick 1965, Miller and Fincke 1999, Sherratt and Forbes 2001, Beukema 2004, Fincke et al. 2007, Van Gossum et al. 2008, Van Gossum et al. 2011). In odonates that have been shown to have character displacement changes in colour are common, as in the change in wing pigmentation in C. aequabilis (Waage 1975a). If reproductive interference is occurring between $N$. irene and $N$ gracilis then character displacement of a visual signal like colour is likely. We sought to quantify any character displacement of visible colour between $N$. irene and $N$ gracilis by scanning the 
thorax of all morphs of both species at allopatric (for N. irene) and sympatric sites. We then analysed thorax colour and compared RGB colour tones between groups.

\subsection{Methods}

\section{Field Study 1}

Field work was conducted during the odonate reproductive season (July - August) in 2010 at Herbert's Bog $\left(44.498507^{\circ} \mathrm{N},-76.415822^{\circ} \mathrm{W}\right)$, and Barb's Marsh $\left(44.523815^{\circ} \mathrm{N}\right.$, $-76.373870^{\circ} \mathrm{W}$ ) at Queens University Biological Station (QUBS), Ontario. Herbert's Bog is a sympatric site where both $N$. irene and $N$. gracilis reside while Barb's Marsh is an allopatric site for $N$. irene. Damselflies are known to disperse very short distances although dispersal distances of $1 \mathrm{~km}$ have been recorded (Watts et al. 2004). Since these sites are approximately 4.5 kilometers apart dispersal and gene flow is expected to be limited. In addition, $N$. irene have most likely been the only Nehalennia species at Barb's Marsh (allopatric site) for generations, as $N$. gracilis is a bog specialist and would not colonize this location.

Density sweeps were performed mid-season following the methodology of Van Gossum et al. (2007). These sweeps were completed in order to obtain baseline estimates of population density, male density, andromorph frequency and operational sex ratio that may contextualise the data, confirming for instance what species and what morph is more common. A density sweep was executed by moving insect nets in a back and forth sweeping pattern over the grasses in the pond, while the sweeper moved at a moderate pace in a linear transect. The sweeper walked for approximately 1 minute, time was taken in seconds. The target species of damselflies were tallied by mature/immature, sex 
and morph and released. Sweeping was continued until at least 10 andromorphs (the rarest phenotype) had been found in order to calculate accurate sex and morph ratios. Time was tallied in order to have an estimate of effort to compare between locations. Sweeps were done in areas of the pond used for the presentations described below.

\section{$\underline{\text { Sexual behaviour }}$}

Mate choice occurs when the male displays sexual behaviour towards the potential mate (hereafter "models"). Sexual behaviour was defined as successful or unsuccessful tandem formation of the responding male on the model. Successful tandems involved the formation of sentinel position, with the response male clasping the model's prothorax with its paraprocts and standing perpendicular to the model. Unsuccessful tandems were when the response male tried to clasp the potential mate's prothorax with their paraprocts but were unable to form the sentinel position. Unsuccessful tandems were interpreted as a sexual behaviour, as males are unable to form sentinel position with males or other species but are demonstrating their choice by trying to form a copulatory position with the potential mate.

Non-sexual behaviour includes several different outcomes by the response male: (i) the response male may not react to the model by continuing to perch without moving for the duration of the presentation, (ii) the response male may fly away out of visual contact with the female (at minimum 4 body lengths away, including different heights or directions from the female), (iii) the male may clasp the thorax of the model without attempting to clasp the prothorax of the model with his paraprocts, (iv) the response male may touch or make contact with the model, or (v) the male may display aggressive behaviour or predate the model. 


\section{$\underline{\text { Stick presentations }}$}

Sexual behaviour was tested through the method of "stick presentations". All potential mates were collected through netting with large diameter butterfly nets. Sticks were locally collected stems of bulrush (Scirpus sp.) of greater than $30 \mathrm{~cm}$ in length. Models were glued by the underside of the thorax using small amounts of UHU rubber cement at an angle mimicking the natural angle of a damselfly perched on grass.

Models were presented level and slowly to within two body lengths of a randomly chosen reproductively mature response male to avoid startling the response male. The response males were within 10 meters of the shoreline and generally accessible to the presenter. Response males were given a period of 120 seconds to respond to the model. The response male's behaviour and its latency were recorded according to the categories described above. If the response male was startled by the presenter or the model, or the response was not recorded, the male was allowed to re-perch and settle and the model was presented again. If the response male flew out of sight during the trial a new response male was chosen to finish the block.

\section{Male mate choice design}

Live $N$. irene males, $N$. irene gynomorphs and $N$. gracilis males were presented as models to response males ( $N$. irene and $N$. gracilis males). Male models were chosen for presentation to complete the work of Van Gossum et al. (2007) who did not present male models (Field Study 2). Gynomorphs were presented in order to test our ability to combine our data with this previous work. Each model was presented to 5 different response males of one of the species in order to average the tandem attempt rate per individual model. If a model died before 5 trials were completed the data was discarded 
and a new model caught. Presentation of models to response males was randomized by model and by species of response male. N. gracilis models used at Barb's Marsh were collected at Herbert's Bog, placed in clear plastic bags filled with air and containing grass stems for perching and kept cool until use at Barb's Marsh. In order to vary the time of day of sampling at both locations, in some instances, $N$. gracilis males were brought back to QUBS and kept cool in the refrigerator until use the next morning.

\section{$\underline{\text { Environmental variables }}$}

Testing was conducted on warm days $\left(>20^{\circ} \mathrm{C}\right.$ ) without high wind strength (Beaufort scale $<3$ ) between the hours of 9 am and 4 pm to ensure the proper environmental conditions for reproductive behaviour. Each day cloud cover was estimated and recorded. Maximum and average temperature $\left({ }^{\circ} \mathrm{C}\right)$ and daily rainfall $(\mathrm{mm})$ were taken from Hartington IHD weather station (44 25'41.028” N by 7641 '25.086” W), approximately $23.8 \mathrm{~km}$ distance from Herbert's Bog, provided by the National Climate Data and Information Archive.

\section{$\underline{\text { Statistical analysis }}$}

The symbols used to represent the different phenotypes are $\mathrm{G}$ for gynomorphs, A for andromorphs, males by an $\mathrm{M}$ and $N$. gracilis females by the symbol F. Species are labelled as ' $N$. gracilis' or ' $N$. irene'. The males' responses to each individual model were coded as sexual or non-sexual behaviour and the proportion of presentations on which a male exhibited sexual behaviour (average number of tandem attempts) was calculated for each model (N. irene gynomorph, male and $N$. gracilis male). Therefore, each model was treated as a replicate. Only complete trials of each model (with 5 response males) were included in the analysis (Table 2-1). 


\section{Field Study 2}

Van Gossum et al. (2007) collected data on male responsiveness using stick presentations during the 2004 field season at the same location (Herbert's Bog) as the present study. In Van Gossum et al. (2007) both $N$. irene and $N$. gracilis males were presented with female morphs including $N$. irene gynomorphs and andromorphs, and $N$. gracilis females (Field Study 2). Each model was presented to three response males for average tandem attempt rate. Sexual responses by the male were coded as in the present study (Field Study 1). N. irene gynomorph presentations to both males were used to see if male responses to gynomorphs were comparable between years and that we were able to include data from Van Gossum et al. (2007) (Field Study 2) into the present study's (Field Study 1) analysis. 
Table 2-1. Summary of sample sizes for models and response males. Samples from 2010 are from the present study. Samples from 2004 are from Van Gossum et al. (2007).

\begin{tabular}{|l|l|l|}
\hline Herbert's Bog (Sympatric) & N. irene male & N. gracilis male \\
\hline N. irene male (2010) & 16 & 17 \\
\hline$N$. irene gynomorph (2010) & 16 & 14 \\
\hline N. irene gynomorph (2004) & 19 & 19 \\
\hline$N$. irene andromorph (2004) & 17 & 17 \\
\hline N. gracilis male (2010) & 15 & 14 \\
\hline$N$. gracilis female (2004) & 19 & 19 \\
\hline Barb's Marsh (Allopatric) & $N$. irene male & N. gracilis male \\
\hline$N$. irene male (2010) & 18 & N/A \\
\hline$N$. irene gynomorph (2010) & 19 & N/A \\
\hline$N$. gracilis male (2010) & 19 & N/A \\
\hline
\end{tabular}




\section{$\underline{\text { Comparison between field studies }}$}

Data appeared to be non-normal, and so non-parametric tests were used for analysis. As Van Gossum et al. (2007) sampled in a different year (2004) to the present study (2010), the rate of response to $N$. irene gynomorph females by $N$. irene and $N$. gracilis males was compared between years using a Mann Whitney U test.

\section{$\underline{\text { Mate discrimination }}$}

We used a non-parametric Kruskal-Wallis test to look for discrimination between models by response males at both locations. Once significance across species and morph was determined pairwise comparisons between models by each response male were analysed using Mann Whitney $\mathrm{U}$ and a Bonferroni correction applied to determine differences between number of tandem attempts between each species and model.

\section{$\underline{\text { Comparison between locations }}$}

The second part of the experiment was to compare sexual behaviour at a sympatric location, where each species has experience discriminating its conspecific female from heterospecific noise, with allopatric locations with inexperienced males. Kruskal-Wallis tests were used to compare male sexual behaviour towards each model ( $N$. irene males, gynomorphs and $N$. gracilis males) between locations.

\section{$\underline{\text { Environmental variables }}$}

Cloud cover $(\%)$, daily mean and max temperature $\left({ }^{\circ} \mathrm{C}\right)$ and daily precipitation $(\mathrm{mm})$ were analysed using Pearson's R for environmental effects on male activity levels (number of male tandem attempts). Of the two temperature variables, daily maximum temperature is a better estimate of temperature as presentations were performed through the hottest part of the day (between 9am and 4pm) and so was used for analysis. 


\section{Character displacement}

As odonate colour changes dramatically after death models were captured and kept alive until scanned. In the field live models were kept cool in air filled bags, with grass stems for the damselflies to perch on, and taken to Queen's University Biological Station. Each specimen was individually freeze killed in a standard refrigerator freezer and immediately scanned to reduce colour change. Live scans were not used as focus and sharpness were impaired due to movement of the specimen during the scanning process. Scans were taken of the left thorax unless damaged and then scans of the right hand thorax were taken. Digital scans were taken at $2400 \mathrm{dpi}$, labelled and checked for sharpness and focus (Figure 2-1). Three 20 by 20 pixel squares were chosen from each thorax so that three samples would fit on the thorax and colour was consistent in that no out of focus or damaged sections were included. Each square was analysed with the program ImageJ for maximum, minimum and average RGB (red blue green) wavelengths (Figure 2-1). The three peak measurements for each colour were averaged per individual for analysis through principle components analysis (PCA). Maximum, minimum and average RGB colour between phenotypes was compared using multivariate analysis of variance (MANOVA). Pairwise comparisons between phenotypes was completed using MANOVA and a Bonferroni correction applied due to multiple comparisons. To test for character displacement, the most important MANOVA comparisons were between allopatric and sympatric sites, and between $N$. irene and $N$. gracilis females at the sympatric site. All analyses were completed with R version 3.0.1 'Good Sport' (R Core Development Team 2013). 


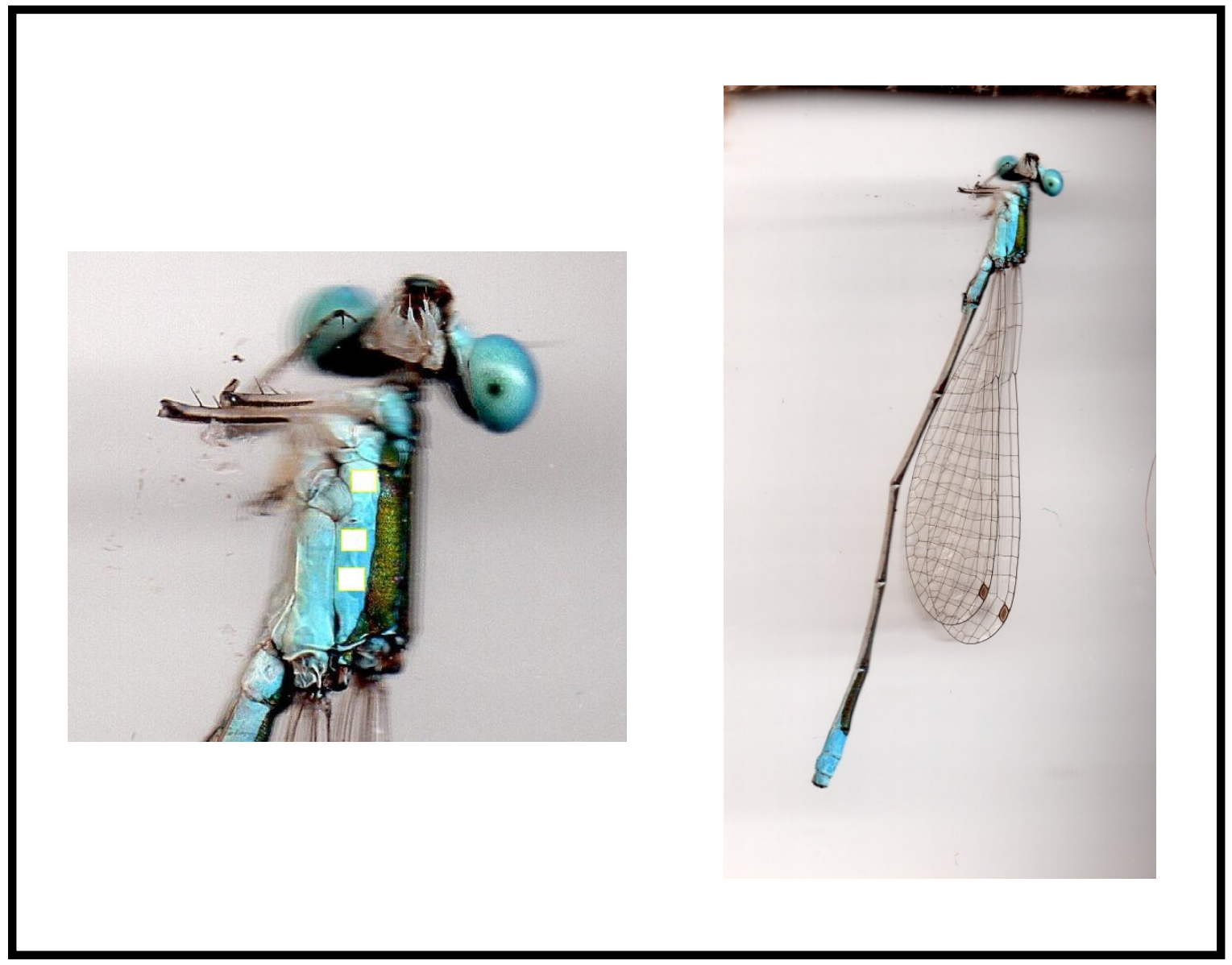

Figure 2-1. An example of a 2400 dpi scan of the left thorax and three 20 by 20 pixel areas selected for analysis with ImageJ. Scan is of a N. gracilis male from Herbert's Bog. 


\subsection{Results}

\section{$\underline{\text { Study comparison }}$}

To assess whether we could combine the data from Van Gossum et al. (2007) with the results of our own study we compared mean mating rates of both $N$. irene and $N$. gracilis males on gynomorphs. $N$. irene males had a higher estimated mean mating rate $(2010=0.61 \pm 0.04,2004=0.65 \pm 0.08)$ than $N$. gracilis males $(2010=0.21 \pm 0.05$, $2004=0.21 \pm 0.06)$ for both years. We found that the rate of tandem attempts of both males towards $N$. irene gynomorph females was not statistically different between years $\left(\mathrm{U}_{\text {irene }}=108, \mathrm{p}>0.05, \mathrm{~N}=19,16 ; \mathrm{U}_{\text {gracilis }}=122, \mathrm{p}>0.05, \mathrm{~N}=19,14\right.$; Figure 2-2). This indicates we can combine results between studies. 


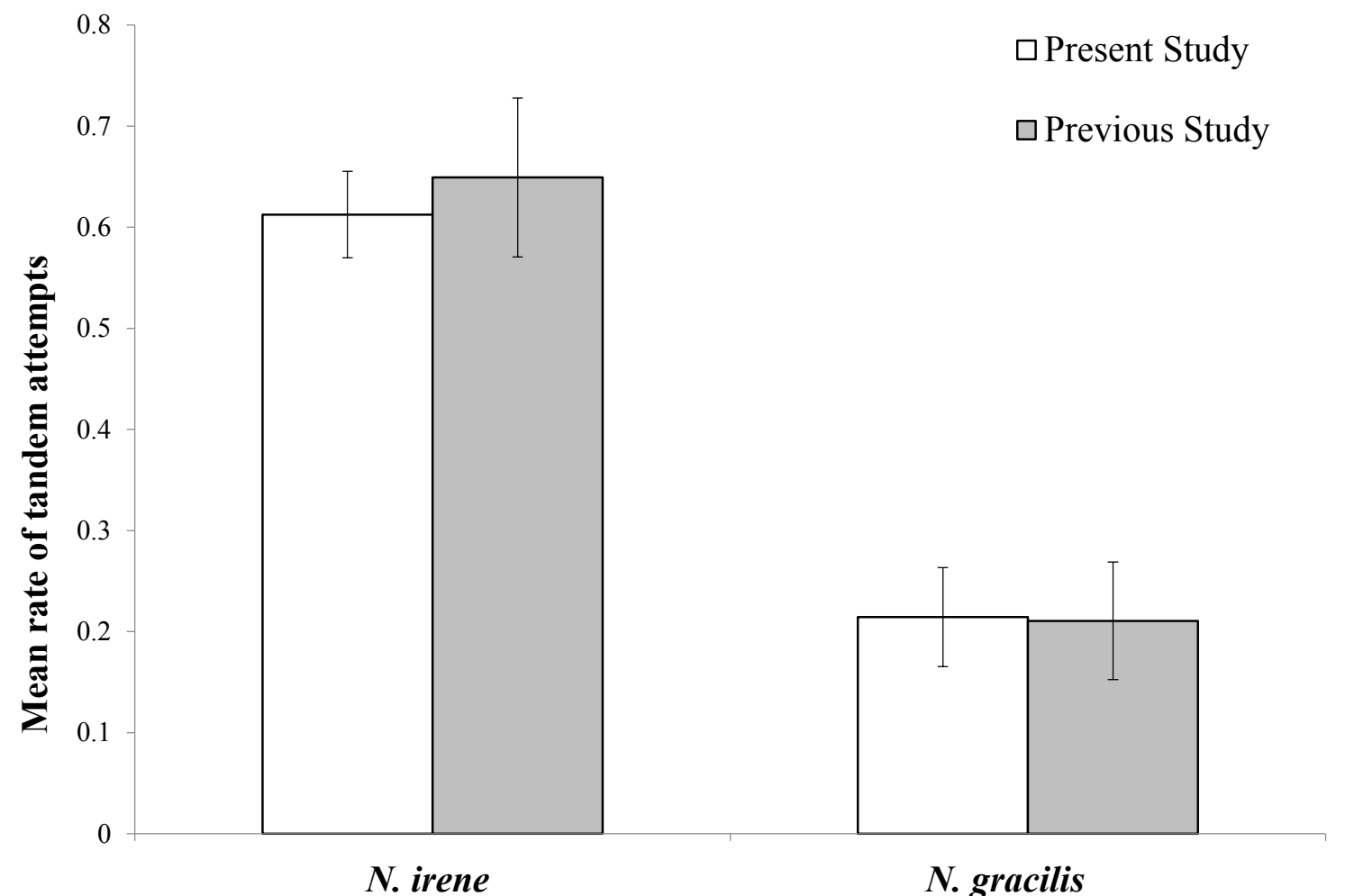

Figure 2-2. Comparison of the mean rate of tandem attempts (mean $\pm 1 \mathrm{SE})$ by male $N$. irene $(\mathrm{n}=19,16)$ and $N$. gracilis $(n=19,14)$ on $N$. irene gynomorphs at Herbert's Bog. $\left(U_{\text {irene }}=108, p>0.05, d f=19,16\right.$; $\mathrm{U}_{\text {gracilis }}=122, \mathrm{p}>\mathbf{0 . 0 5}, \mathrm{df}=\mathbf{1 9 , 1 4}$ ). Previous study data (white) was collected in 2004 by Van Gossum et al. 2007 (Field Study 2). Present study data (Field Study 1) was collected in 2010 (grey). 


\section{$\underline{\text { Male response behaviour }}$}

The frequency of male response to models varied by model and location. At a sympatric site, both $N$. irene and $N$. gracilis have experience with the other species so it is expected that the highest degree of discrimination would occur at this location compared to allopatric locations. We found that male $N$. irene attempts differed significantly across species and morph (Kruskal-Wallis, $\mathrm{H}=27.27, \mathrm{df}=5, \mathrm{p}<0.001)$. Specifically male $N$. irene made significantly more tandem attempts with conspecific gynomorphs (G: Mann Whitney $U=920.8, p=0.001, N=16,16$; $G^{1}$ : Mann Whitney $U=230.5, p=0.05, N=19,16$; Figure 2-3a, ${ }^{1}$ VanGossum et al. 2007) than on conspecific males and heterospecifics. However, there was no significant difference in number of tandem attempts between andromorphs and gynomorphs (G: Mann Whitney $U=103, p>0.05, N=16,17$; $\mathrm{G}^{1}$ : Mann Whitney $\mathrm{U}=217, \mathrm{p}>0.05, \mathrm{~N}=19,17$; Figure 2-3a). N. irene males appeared to be able to distinguish conspecific females from the other phenotypes. Out of 409 presentations males responded sexually $45 \%$ of the time. Of these sexual responses the majority were directed towards conspecific mates (60\%), with only $40 \%$ of sexual responses exhibited for heterospecifics and conspecific males. Interestingly, male $N$. irene differed in their rate of missed opportunities to mate with conspecific mates between the two morphs. $N$. irene males refused to mate with gynomorphs in $36 \%$ of presentations compared to refusing to mate with $55 \%$ of andromorph models. 
a.

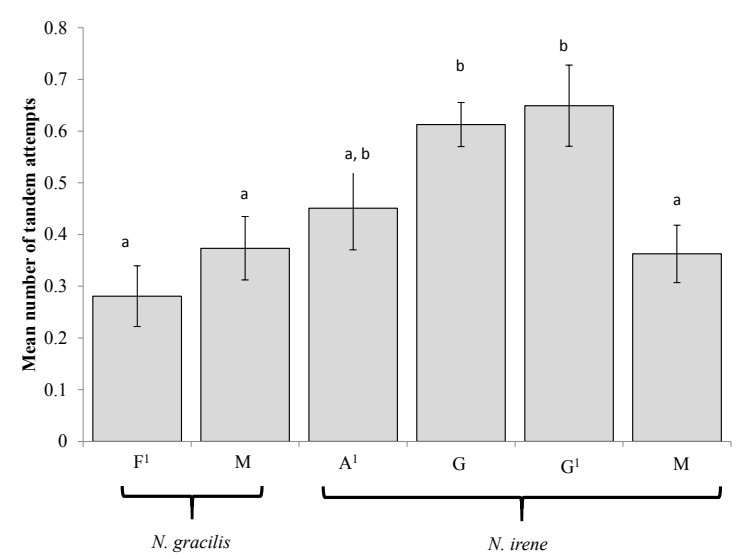

b.

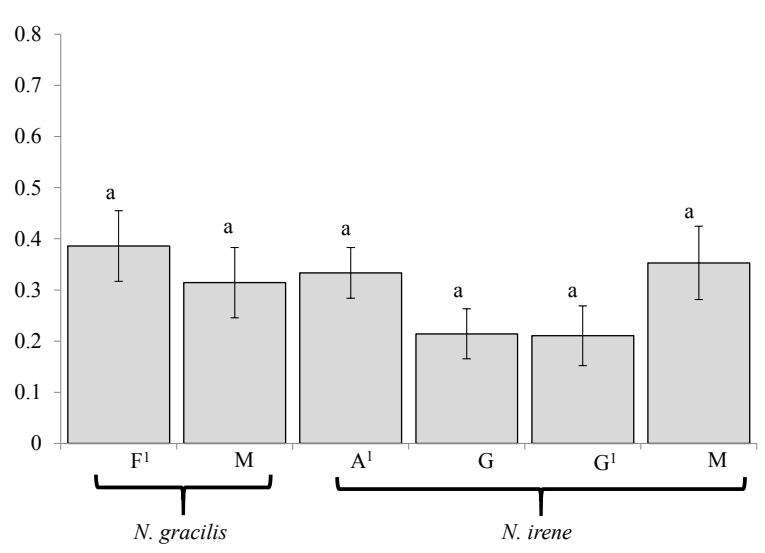

Figure 2-3. a. The mean number of tandem attempts by $N$. irene response males (mean \pm 1 SE) on each morph at a sympatric site. $b$. The mean number of tandem attempts by $N$. gracilis response males $( \pm$ SE) on each morph at a sympatric site. $F=$ female, $M=$ male, $A=$ andromorph, $G=$ gynomorph.

${ }^{1}=$ data obtained by Van Gossum et al. 2007 . Letters indicate non-statistically significant pairwise comparisons. 
At the sympatric site $N$. gracilis males' ability to discriminate between all presented phenotypes approached significance (Kruskal-Wallis $\mathrm{H}=5.29, \mathrm{p}=0.07, \mathrm{df}=5$, Figure 2-3b). $N$. gracilis males had the highest mating rate with their own females $(0.39 \pm 0.069$ tandem attempts) and andromorphs ( $0.33 \pm 0.050$ tandem attempts). They were least likely to respond to yellow gynomorphs $(0.21 \pm 0.050$ tandem attempts). Overall, $N$. gracilis males were unable to detect their own female from the models presented (Figure 2-3b).

Barb's Marsh is a previously untested allopatric site for $N$. irene where $N$. irene has no experience with discriminating between $N$. irene and $N$. gracilis morphs $(N$. gracilis does not occur). Andromorph density is also very low, with andromorphs making up $1.1 \%$ of the population and $4.8 \%$ of available females. Due to this lack of experience we expect that $N$. irene will attempt tandems with $N$. gracilis at the same rate as its own females. Comparison of responses by $N$. irene males on $N$. irene gynomorph, male and $N$. gracilis male models (Kruskal-Wallis $\mathrm{H}=5.29, \mathrm{df}=2, \mathrm{p}=0.071$, Figure 2-4) indicated no difference in mean number of mating attempts between models. This is different in comparison to Herbert's Bog (sympatric site) where $N$. irene males were able to discriminate males from gynomorphs. 


\section{Differences in mating activity}

The second part of the experiment was to compare sexual behaviour between a sympatric location, where each species has experience discriminating its conspecific female from heterospecific noise, with an allopatric location with inexperienced males. We found that males from Herbert's Bog were twice as active, or are twice as likely to initiate tandems with gynomorphs as males at Barb's Marsh (Mann Whitney $U=66.5, p<0.05, d f=16,19$, Figure 2-4a). In order to account for the differences in activity level between the two locations we calculated the proportion of the mean number of tandem attempts over total male tandem attempts at each location (Figure 2-4b). Overall we found that there was no difference in the proportion of tandem attempts or preferences between locations for $N$. irene males, gynomorphs or N. gracilis males (Figure 2-4b).

In addition, at Herbert's Bog $N$. irene males displayed a population-level preference for gynomorphs (2004) and gynomorphs and andromorphs (2010) over males and heterospecifics. In comparison, at Barb's Marsh we see that male preference for gynomorphs is non-significant over conspecific and heterospecific males (Kruskal-Wallis $\mathrm{H}=5.29, \mathrm{df}=2, \mathrm{p}=0.071$, Figure 2-4a). Males at Barb's Marsh seem to be much less active than at Herbert's Bog and have a higher rate of refusal to all models presented than males at Herbert's Bog (Figure 2-4a). 

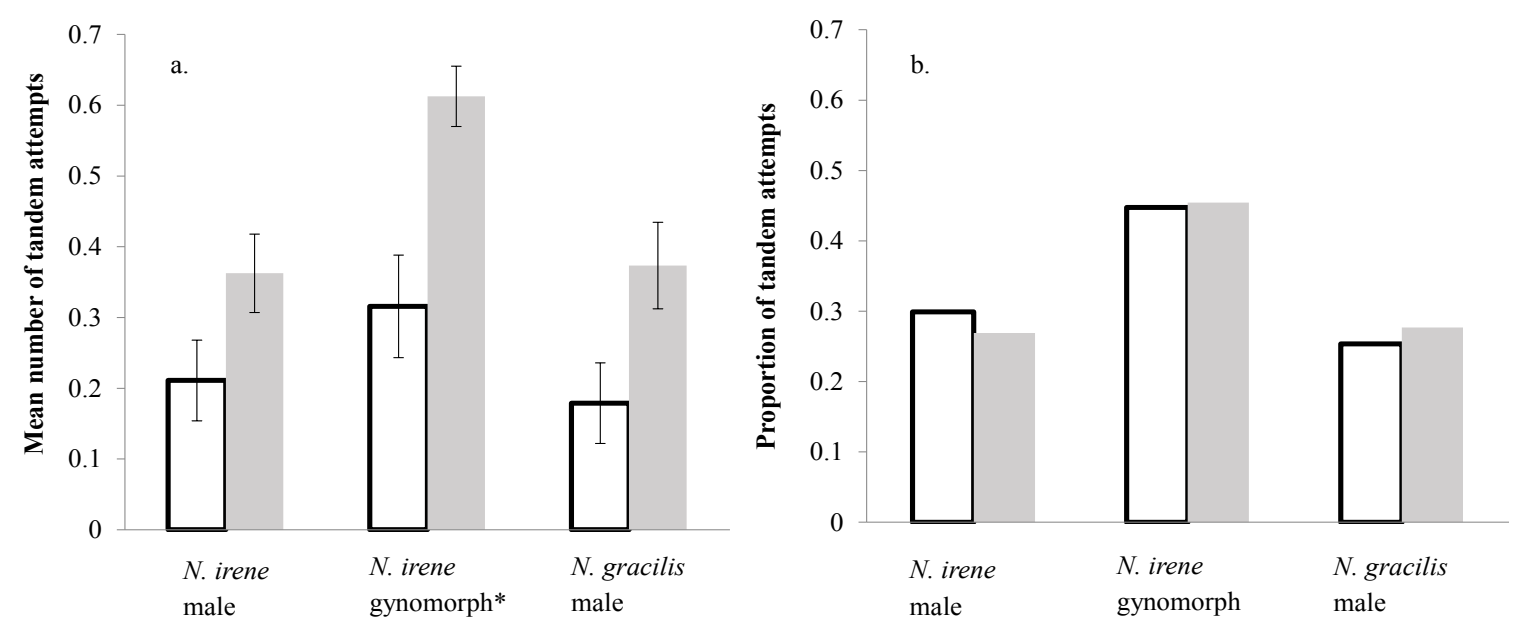

Figure 2-4. a. Comparison of mean number of tandem attempts by $N$. irene males (mean $\pm 1 \mathrm{SE}$ ) and b. Comparison of proportion of total tandem attempts by $N$. irene males between allopatric and sympatric sites. White bars are allopatric sites, grey bars are sympatric sites. a. $N$. irene gynomorphs experience significantly different rates of attack between sites (Mann Whitney $U=66.5, p<0.05$, df $=16,19)$ marked with **, 


\section{Environmental variables}

Cloud cover $(\%)$, daily mean and max temperature $\left({ }^{\circ} \mathrm{C}\right)$ and daily precipitation $(\mathrm{mm})$ were analysed for weather effects on male activity (number of tandem attempts, Table 22). Both mean and daily maximum temperature had a significant correlation with male activity (mean: $\mathrm{R}=-0.2053, \mathrm{p}=0.007, \mathrm{df}=148$, $\max : \mathrm{R}=-0.205, \mathrm{p}=0.006$, $\mathrm{df}=148$ ) with a decrease in male activity with increasing temperature. 
Table 2-2. Pearson correlation $(R)$ between environmental variables (Tmean, Tmax, precipitation) and male activity (mean number of tandem attempts).

\begin{tabular}{|l|l|l|}
\hline Variable & $\mathrm{R}$ & $\mathrm{p}$ \\
\hline $\mathrm{T}_{\text {mean }}\left({ }^{\circ} \mathrm{C}\right)$ & -0.203 & 0.007 \\
\hline $\mathrm{T}_{\max }\left({ }^{\circ} \mathrm{C}\right)$ & -0.205 & 0.006 \\
\hline Precipitation $(\mathrm{mm})$ & -0.114 & 0.084 \\
\hline
\end{tabular}




\section{Character Displacement}

There was a significant difference in RGB colour between phenotypes (Pillai's Trace, $\mathrm{F}=$ 3.90, $\mathrm{df}=2,4, \mathrm{p}=<0.001$, Table 2-3). Pairwise comparisons of morphs using a MANOVA with Bonferroni correction show two trends (Table 2-3). First, comparisons with gynomorphs indicated significant differences in colour compared to other phenotypes (Table 2-4). PCA of colour showed similar results in that gynomorphs were different than all other phenotypes and grouped separately (Figure 2.5). This is due to the yellow tones of gynomorphs in comparison to the blue tones of all other phenotypes. Secondly, comparison of $N$. irene males with $N$ gracilis males indicated a significant difference in thorax colour (Table 2-3). This difference is similar to gynomorphs in that $N$. irene males, on average, have more yellow tones while $N$. gracilis males exhibited more blue tones in their thoraxes. In comparison, PCA grouped all other phenotypes together as indistinguishable based on peak RGB wavelengths (Figure 2.5). This indicates male $N$. irene are potentially distinguishable from $N$. gracilis males using visual colours.

However, this also suggests female blue-black phenotypes are indistinguishable by RGB thorax colour for males. Comparisons between locations, over all $N$. irene morphs, approached significance (Pillai's Trace, $F=2.229, \mathrm{df}=2,4, \mathrm{p}=0.092$ ) but overall there were no differences in thorax colour between allopatric and sympatric $N$. irene damselflies. 
Table 2-3. Summary of pair wise comparisons of thorax colour using MANOVA. Bonferroni correction requires a $\mathrm{P}$-value of $\mathbf{0 . 0 0 5}$ for significance. Significant comparisons are in bold and marked with an '*',

\begin{tabular}{|c|c|c|c|c|c|c|c|c|c|c|}
\hline \multirow{2}{*}{ Pillai's Trace } & \multicolumn{2}{|c|}{ N. gracilis male } & \multicolumn{2}{|c|}{$\begin{array}{l}\text { N. gracilis } \\
\text { female }\end{array}$} & \multicolumn{2}{|c|}{$N$. irene male } & \multicolumn{2}{|c|}{$\begin{array}{l}N . \text { irene } \\
\text { gynomorph }\end{array}$} & \multicolumn{2}{|c|}{$\begin{array}{c}N . \text { irene } \\
\text { andromorph }\end{array}$} \\
\hline & Pillai & $\mathrm{P}$ & Pillai & $\mathrm{P}$ & Pillai & $\mathrm{P}$ & Pillai & $\mathrm{P}$ & Pillai & $\mathrm{P}$ \\
\hline $\begin{array}{l}\text { N. gracilis } \\
\text { male }\end{array}$ & --- & --- & 0.258 & 0.179 & 0.528 & $<0.001 *$ & 0.754 & $<0.001 *$ & 0.293 & 0.219 \\
\hline $\begin{array}{l}\text { N. gracilis } \\
\text { female }\end{array}$ & 0.258 & 0.179 & --- & --- & 0.532 & 0.008 & 0.747 & 0.006 & 0.961 & 0.161 \\
\hline$N$. irene male & 0.528 & $<0.001 *$ & 0.532 & 0.008 & --- & --- & 0.786 & $<0.001 *$ & 0.623 & 0.015 \\
\hline $\begin{array}{l}N \text {. irene } \\
\text { gynomorph }\end{array}$ & 0.754 & $<0.001 *$ & 0.747 & 0.006 & 0.786 & $<0.001 *$ & --- & --- & 0.878 & 0.035 \\
\hline $\begin{array}{l}N \text {. irene } \\
\text { andromorph }\end{array}$ & 0.293 & 0.219 & 0.961 & 0.161 & 0.623 & 0.015 & 0.878 & 0.035 & --- & --- \\
\hline
\end{tabular}




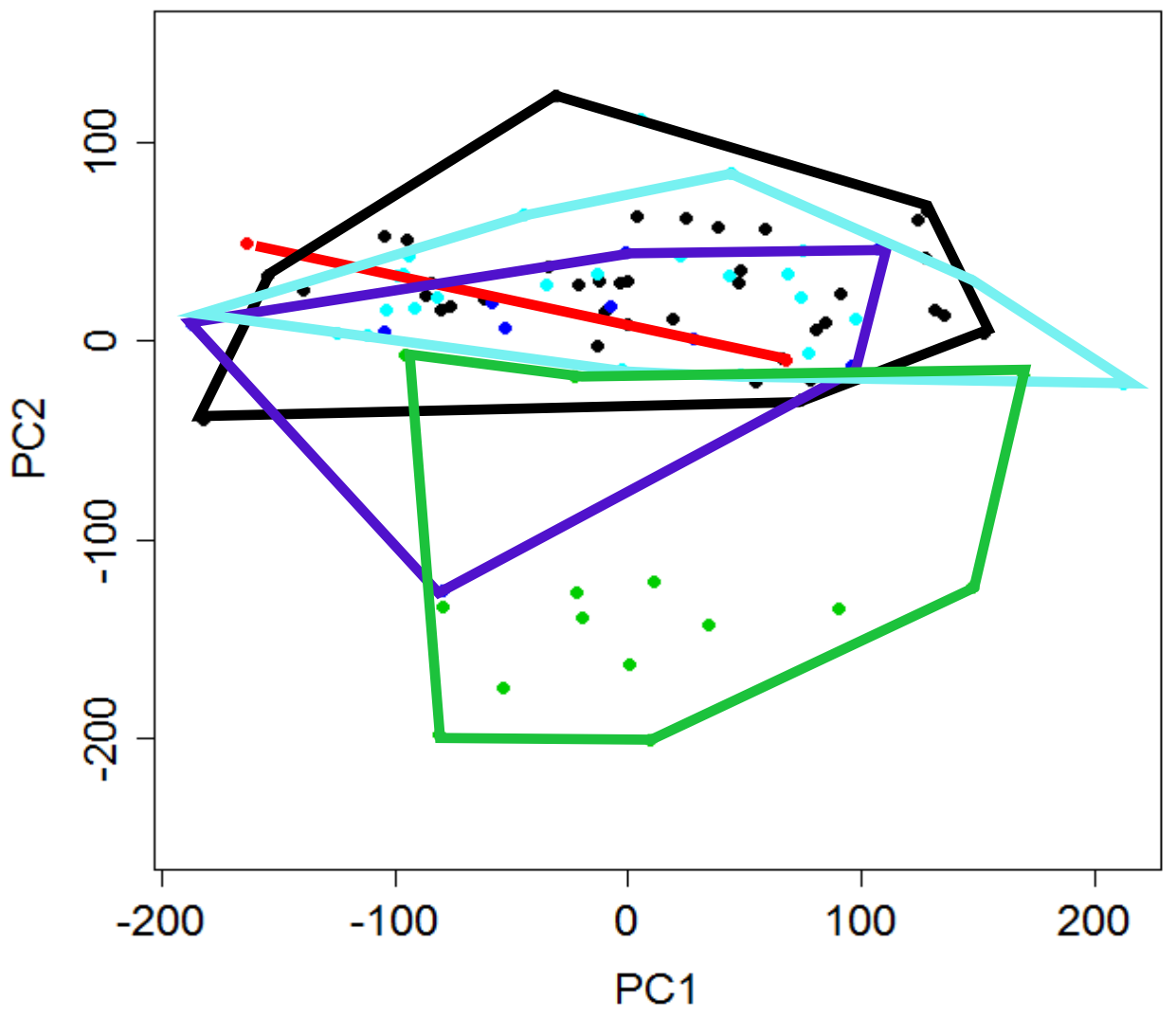

- N. gracilis female

- N. gracilis male

- N. irene andro

- $N$. irene gyno

- N. irene male

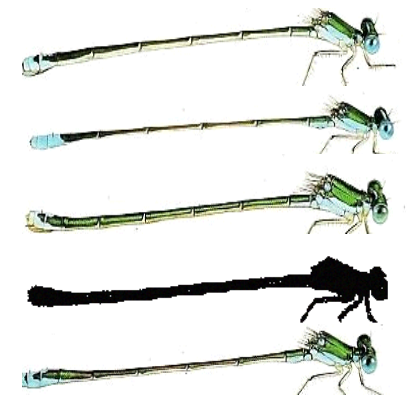

Figure 2-5. PCA analysis of colour of $N$. gracilis males and females and $N$. irene males, andromorphs and gynomorphs. Convex hulls show overlap between phenotypes. 


\subsection{Discussion}

\section{$\underline{\text { Male Mate Discrimination }}$}

At a sympatric site, $N$. irene preferred to mate with gynomorphs over males and heterospecifics. However, $N$. gracilis males were equally likely to mate with heterospecifics as conspecifics. Both males attempted tandems with all phenotypes.

Since $N$. irene is more common than $N$. gracilis at sympatric sites they were expected to have increased false alarms on presentation compared to $N$. gracilis. This was not supported by the results of our study. $N$. gracilis males had a much higher rate of inappropriate mating attempts on presentation compared to $N$. irene males and were equally willing to attempt to mate with all potential mates. As $N$. gracilis are rare in this system we expected them to be more selective and therefore have a higher signal detection threshold. However, if females are so rare that the cost of missed opportunities to mate is greater than the cost of a false positive for males, then their low signal detection threshold would be maintained (Johnstone et al. 1996). The density of $N$. gracilis females is extremely low (1\%) relative to all potential mates, due to the large $N$. irene population, so the chance of encounter with $N$. gracilis males may be low enough that males cannot lose an opportunity to mate with a female. Models of mating strategies have found that with low encounter rates persistence by males is one way to males can optimize their mating success (Parker 1974, Shuster and Wade 2003). In odonate systems Fincke (2004) hypothesized that, at low population densities the cost of a missed opportunity to mate is maximal, as a missed opportunity could be the only opportunity that male gets to mate. Persistence by males in the face of high cost of opportunities to mate is a common strategy in many species. In addition, although $N$. gracilis appears not 
to distinguish its own mate from others, our results show that they are motivated to mate with their own females; out of all available models males had the lowest rate of missed encounters with their own female.

$N$. irene males most often attempted mating with conspecific females over all potential mates. This is a result of their ability to discriminate their gynomorphs from all other potential mates. With removal of sexual activity towards gynomorphs, $N$. irene males have the same rate of false alarms to blue-black phenotypes as $N$. gracilis males using stick presentations. The prediction that $N$. irene would have a low signal threshold is justified by our observations of male mimicking models, in that males make many signal detection errors and have a higher rate of false alarms with males and heterospecifics and many missed opportunities with andromrphs. However, male $N$. irene have a greater detection ability for gynomorphs and miss few opportunities to mate with them. Overall, both males indicate a low signal detection threshold for blue-black phenotypes. These results were similar to the results found in Van Gossum et al. (2007) where $N$. irene males were able to distinguish yellow gynomorphs from blue-black models. Additionally they also ascertained that $N$. gracilis males could not distinguish between models. These results are interesting because in a summary analysis of species that make heterospecific matings it was suggested that males of polymorphic species made more mistakes than males of monomorphic species (Miller and Fincke 2004). This study seems to show the reverse trend, that a male with a monomorphic species makes more mistakes than a male with polymorphic females. Although Miller and Fincke (2004) suggested that polymorphic males were more likely to make mistakes, they also found that this pattern only held true for four genera (Lestes, Enallagma, Calopteryx and 
Platycnemis) out of the eight genera examined. They suggested that this was due to the need for males (of Lestes, Enallagma and Platycnemis) to search for mates and an increase in difficulty in learning appropriate females from the different female variants available. As Nehalennia males also search for mates in the same manner as these genera, and both males experienced a range of female variants as potential mates, yet showed the opposite pattern, these justifications are not supported by our work. In the same work Miller and Fincke (2004) suggest that mistakes made by Enallagma males are most common when female densities are low indicating that the cost of a missed opportunity to mate is higher than the cost of making a mistake. Our data support this interpretation that for any species, when the cost of a mistake is less than the cost of a missed opportunity to mate, a male should lower their signal detection threshold and increase their rate of false alarms.

At our allopatric site $N$. irene males would have no experience with $N$. gracilis models and very little experience with their own andromorph female. They would be expected to make mistakes between models due to this lack of experience. $N$. irene males do have a high rate of false alarms in stick presentations with no ability to distinguish between the potential mates presented. In this case male $N$. irene demonstrate an inability to distinguish their gynomorph from the noise supplied by other models. Surprisingly males also frequently missed opportunities to mate with its own gynomorph. Males at Barb's Marsh seemed to have a lower activity level, and a resulting lower mating rate with all morphs, which seems to explain their high rate of missed opportunities. Bogs and marshes have many environmental differences in water chemistry, habitat and their food webs. Most likely an environmental difference in 
habitat or other cue explains the differences in male activity level between these two locations.

Overall, $N$. irene differentiates between its gynomorph and other mating options. However, it does not differentiate between its andromorph and other similarly coloured mates. This suggests that andromorphs are good mimics of males. It also suggests that local conditions, the noise created by the presence of sympatric species need to be considered when looking at signal detection based hypotheses.

It would be interesting to compare the rates of harassment on andromorphs and heterospecifics between allopatric and sympatric locations. Ting et al. (2009) found that as andromorph frequencies increased tandem attempts on both females and males also increased. In sympatric locations there would be more noise for males than at allopatric locations. We would predict these locations have higher rates of harassment due to the increased frequency of encounters with blue black models, similar to locations with higher densities of andromorphs relative to gynomorphs. If andromorphs experience higher levels of harassment due to the overall higher frequency of models than all models would experience the same higher level of male harassment. This increased level of harassment should cause interference in sympatric species.

Although reproductive interference seems to be occurring between $N$ irene and $N$ gracilis, our results on colour do not indicate character displacement for colour for $N$. irene at these two sites. However, females could be using other alternative strategies to prevent reproductive interference. They could be segregating themselves spatially or across time. Females could use species specific behavioural cues to indicate readiness to mate. It has been noted that the flight and motion of individuals may cue males at speeds 
and distances over which colours cannot be seen (Olberg et al. 2000, Greenfield 2002, Fincke 2004). It has also been speculated that odonates do have the capacity of smell and may use scent for identification (Stoks 1998, Bots et al. 2009b, Iserbyt and Van Gossum 2011). Males can use tactile cues to identify females. Both the use of their cerci and sensory apparatus on their genitalia can be used to identify females (Uhia and Rivera 2005, McPeek et al. 2011). In Nehalennia species, differences in female pronotums create a lock and key mechanism with male paraprocts that can be used for identification (Sherratt and Wilkinson, 2009). In addition, character displacement could be occurring for other morphological features such as abdomen patterning, UV colouration or wing features not tested in this study. 


\section{Chapter: The maintenance of female polymorphisms by mate choice}

\subsection{Abstract}

In odonates, female polymorphisms are thought to have arisen in order to avoid male harassment; so the different female morphs represent distinct strategies that influence male mate seeking and mate choice to reduce harassment. The andromorph is similarly coloured to the male while the gynomorph is not. Two theories have been proposed to explain female polymorphism in damselflies, the male mimicry (MM) and learned mate recognition hypothesis (LMR). To test the predictions of these hypotheses I examined the rate of sexual response of individual males over multiple encounters with both female morphs and males in Nehalennia irene. The male mimicry theory (MM) predicts that an individual reproductively active male will attempt to mate with any female he recognizes, with andromorphs sometimes being confused for males. However, the learned mate recognition theory (LMR) predicts that reproductively active males will specialize on one morph and reject the other morph in subsequent encounters. I presented individual males with 6 models (2 gynomorphs, 2 andromorphs and 2 males) to test whether males are more or less likely to mate with given morph. The most important factor to affect a male's sexual response was the behaviour of the model, but there was no evidence that individual males specialize on one morph over another. In this respect, the results are inconsistent with the LMR hypothesis. 


\subsection{Introduction}

Sex-limited polymorphism occurs when there are two or more phenotypically dissimilar types of one sex (Ford 1957, Bots et al. 2009c). In damselflies, particularly in Coenagrionidae, female polymorphisms are common, with the presence of two (and sometimes three) distinct female morphs (Forbes 1991b, Fincke et al. 2005). Female morphs that are phenotypically similar in body colour and pattern to the male (to human eyes) are referred to as andromorphs while females that are dissimilar are referred to as gynomorphs. These females may also differ in morphology and behaviour (Forbes et al. 1997, Joop et al. 2006a, Gosden and Svensson 2007, Gosden 2009). It is currently believed that female limited polymorphism is controlled at a single autosomal locus, with the number of alleles equalling the number of colour morphs in the species (Johnson 1964, Cordero 1990, Andres et al. 2000, Sanchez-Guillen et al. 2005).

Since female polymorphism seems to have arisen in many species as a consequence of sexual selection (Andres et al. 2000) it has been widely hypothesized that the polymorphism has been generated as a response to male mate choice. In Odonata male mate choice has been demonstrated to occur, with males exhibiting preferences for one morph over the other(s) (Fincke 2004, Van Gossum et al. 2005a). Indeed, it is widely believed that female limited polymorphisms have arisen as a result of male harassment (Robertson 1985, Gosden and Svensson 2007, 2009, Iserbyt and Van Gossum 2009, Takahashi et al. 2012). Male harassment occurs because females tend to be the rarer sex in this system, at least operationally. Thus, receptive females come to the edges of ponds to mate with males and for oviposition sites. Once females oviposit they leave this area, and due to the shortage of females they may be attacked by mate seeking males. 
To maximize their reproductive success, reproductively active males are motivated to mate with as many females as possible and should mate on each encounter to maximize mating rate. On the other hand, females need only one male to fertilize all their eggs, and need fewer mates over their lifetime (Arnqvist and Nilsson 2000, Arnqvist and Rowe 2005). This disparity between the number of matings that females need for successful reproduction versus the number of matings that males need to maximize their reproductive success leads to male harassment (Fincke 1997). When females leave the pond they are unreceptive for mating but may be attacked and held by males until they give up and release the female. This harassment is detrimental to females (CordobaAguilar and Gonzalez-Tokman 2011) due to of its effect on female's time and energy budgets (including loss of energy while being held and the reduction in feeding time for the female) but also due to the higher risk of predation while in tandem (Zeiss et al. 1999, Takahashi and Watanabe 2010a). In general this can lead to females demonstrating an overall lower fitness than without male harassment (Sirot and Brockmann 2001, Sirot et al. 2003).

Currently there are two main theories explaining the evolution of female polymorphism in damselflies to deal with the high level of male harassment. The malemimic hypothesis (MM) theorizes that male harassment has led one female morph (andromorph) to evolve to be a mimic of the male (Sherratt 2001). Signal detection theory states that the males will confuse the mimic andromorph female for another male, a detection error, lowering her rate of harassment. Some previous studies have shown lower rates of harassment and the resulting increase to fitness of andromorphs compared to gynomorphs (Gosden and Svensson 2009, Takahashi and Watanabe 2010a). Hence, 
when andromorphs are functional male-mimics then they gain a degree of protection from harassment. However, like classical Batesian mimicry the andromorphs's advantage is frequency-dependent, requiring rarity of andromorphs (mimics) relative to males (models) (Sherratt 2001). Some males will not make a signal error but will recognize the female andromorph and mate with her and/or andromorphs can display a clearer signal to males of readiness to mate (Huang and Reinhard 2012). These matings keep the rare andromorph phenotype in the system.

An alternative hypothesis is the learned mate recognition hypothesis (LMR). This postulates that reproductively active males choose between female morphs in a frequency-dependent manner, simply based on previous successful mating experience (Miller and Fincke 1999). In this case the most common form will be targeted by males, increasing selection for that form. Here the form of frequency-dependence in male mate choice rests not on the ratio of andromorphs to males but on the ratio of andromorphs to gynomorphs. Likewise, if damselflies must learn to recognise females and concentrate on the female type with which they have had most experience, then the learning process itself will manifest as non-random selection of morphs, i.e. male mate choice.

Studies have shown rather mixed evidence for both hypotheses (Córdoba-Aguilar 2008). These studies have compared overall mating and harassment rates between potential mates. In particular, several studies have found that males as a whole have preferences for certain types of females (Robertson 1985, Cordero Rivera 1998, Iserbyt and Van Gossum 2011) while other studies found males choose the most common morph (Van Gossum et al. 1999). Importantly however, the vast majority of studies to date have focused on binary choice experiments allowing the male to choose one morph or the 
other, but have not tested for repeatability in male mate choices within an individual male. This omission is important because if, for example, the population as a whole exhibits a mating preference for gynomorphs we still do not know whether all males exhibit the same proportionate preference, or whether individual males differ widely in their mating preference. Learned mate recognition hypothesis predicts that individual males will specialize, and exclusively prefer one morph or the other. However, the male mimicry hypothesis predicts that males will generalize, choosing available mates as they recognize them as females. In addition, if individual males specialize, then a related question in the context of the male mimicry hypothesis is whether andromorph-preferring males also attack males at higher rates than gynomorph-preferring males.

Our research will test if individual male $N$. irene have consistent preferences for a given morph. The unique feature of our research is that we will seek to quantify how the male-mate choice exhibited at the population level might be decomposed into individuallevel effects, i.e. whether all individuals have the same preferences, or whether individuals effectively specialise on one morph or another.

\subsection{Methods}

\section{$\underline{\text { Study Species }}$}

Species and morph descriptions are summarized in the Introduction (Chapter 1 "Study Species". Most importantly $N$. irene has a blue-black male and similarly-coloured female (andromorphs) and a much differently coloured yellow female (gynomorph).

\section{$\underline{\text { Field work }}$}

Field work was conducted during the odonate reproductive season (May - August) in 
2011 at two locations in Ontario: Loch Garry, Alexandria $\left(45.266691^{\circ},-74.681845^{\circ}\right)$ and LeRoi Marsh (Otter Marsh), Queens University Biological Station (QUBS) (44.551310, $\left.-76.371825^{\circ}\right)$. These locations were chosen for their high andromorph densities in previous seasons ( $30-45 \%$ at peak) in order to have access to andromorphs.

Density sweeps were performed at the beginning of each sampling session (approximately weekly), at each location to provide estimates of population density, male density, andromorph frequency and operational sex ratio and thereby allow for any density-dependent effects that may affect the interpretation of our data (Van Gossum et al. 2007). A complete description of density sweeps is found in Chapter 2 ("Field Study $1 ”)$.

\section{Between morph variation}

The experiment was carried out through live stick presentations. This methodology is outlined under the "stick presentations" subsection in Chapter 2-3 Methods section. Male response behaviour was recorded as outlined in "sexual behaviour", also in Chapter 2-3 Methods section.

To test for differences in preference for all possible potential mates for $N$. irene two sets of each morph of $N$. irene (two $N$. irene males, andromorphs and gynomorphs) were used in each block. In each trial, a model (male, andromorph or gynomorph) was presented to a response male of $N$. irene and sexual behaviour noted as described in Chapter 2. After each trial the male test subject was removed extremely gently by pushing him against a nearby grass stem and allowed to resettle on a perch to recover before the next trial (Forbes et al. 1997). Then the next model of the set was presented to the same male and behaviour recorded as in the first trial. This was repeated for all 6 
models. This set of 6 models was presented to each of 6 different response males (36 presentations in total) in each possible order of presentation to complete one block (Table 3-1). Each new block was started with a new set of models and was presented to new response males. Incomplete blocks due to the death of a model during the block were discarded. At the conclusion of a block, all models and response males were immediately preserved in $95 \%$ ethanol for laboratory use. 
Table 3-1. Illustration of one block (all six possible combinations of presentation order) of the design for testing the responsiveness of a male to all three morphs. $(\mathrm{M}=$ male, $\mathrm{A}=$ andromorph, $G=$ gynomorph; numbers refer to individuals).

\begin{tabular}{|l|l|l|l|l|l|l|}
\hline Test Subject & \multicolumn{2}{|l|}{ Test 1 } & \multicolumn{2}{l|}{ Test 2 } \\
\hline RM1 & M1 & A1 & G1 & M2 & A2 & G2 \\
\hline RM2 & A1 & G1 & M1 & A2 & G2 & M2 \\
\hline RM3 & G1 & M1 & A1 & G2 & M2 & A2 \\
\hline RM4 & G1 & A1 & M1 & G2 & A2 & M2 \\
\hline RM5 & A1 & M1 & G1 & A2 & M2 & G2 \\
\hline RM6 & M1 & G1 & A1 & M2 & G2 & A2 \\
\hline
\end{tabular}




\section{Model response behaviour}

As model damselflies could move and possibly display reproductive cues during the presentations this behaviour was noted. The most commonly seen behaviours were abdomen curls and wing flutters. Abdomen curls were when the model curled its abdomen forward to touch its thorax. Wing flutters are brief high speed flutters of all four wings of the model.

In addition, the reproductive state of the models was noted when caught. Models could be caught individually, in a tandem or in copula (in the wheel formation). As it is unknown if models in tandem and copula have already mated with their partner, this may influence the outcome of the presentations. This was coded as $\mathrm{S}$ for individual, $\mathrm{T}$ if caught in tandem, or $\mathrm{C}$ for found in copula.

\section{$\underline{\text { Environmental variables }}$}

Testing was conducted on warm days $\left(>20^{\circ} \mathrm{C}\right)$ without high wind strength (Beaufort scale $<3$ ) between the hours of 9 am and 4 pm to ensure the proper environmental conditions for reproductive behaviour. Before each block, wind speed, cloud cover and ambient temperature at the level of the damselflies in the grass was recorded using a $\mathrm{La}$ Crosse anemometer (Model EA-3010U).

\section{$\underline{\text { Statistical analysis }}$}

Responses were coded either 1 for sexual responses or 0 for non-sexual responses. For each response male the average responsiveness was calculated by averaging its sexual behaviour for the 6 models. The average number of tandem attempts (responsiveness of the male) of each model was calculated by averaging the sexual responsiveness of the 6 response males it was presented to. We then used the non-parametric Mann Whitney U 
to look at pairwise differences in the mean number of tandem attempts of $N$. irene males between andromorph, gynomorph and male models. Analyses were performed using R version 3.0.1 'Good Sport' and Excel Professional Plus 2013. Generalized linear mixed models (GLMM) were used to examine if factors such as environmental variables, female status and behaviour, presentation order, location and block effects had an impact on male $N$. irene sexual activity (Table 3-2, Appendix A). Both full models, including all variables, and null models were calculated. Non-significant variables, computed from the Wald z-statistic, were removed in a step wise manner from the full model until a best model was found. Models with AIC values greater than the full or null models were discarded. Data from both locations was combined as there were no significant differences in responsiveness between sites.

Models indicated that several variables were important in explaining male sexual behaviour. The status of the model on capture (single, tandem or in copula) had an effect on the response male's behaviour. To assess this we compared mean number of tandem attempts between the three groups using a Kruskal Wallis test as our data was nonnormal; models without a known status were disregarded. I took the same set of statistical approaches to test for differences in location, order and environmental variables. 
Table 3-2. Summary of Variables included in modelling in R. For a complete definition of response male behaviour see 'sexual behaviour' in Chapter 2-3 Methods section.

\begin{tabular}{|c|c|}
\hline Variable & Description \\
\hline \multicolumn{2}{|l|}{ Environmental } \\
\hline Wind Speed & $\begin{array}{l}\text { Wind speed measured within the grass at approximately } 20 \\
\mathrm{~cm} \text { from the ground in } \mathrm{m} / \mathrm{s}\end{array}$ \\
\hline Cloud Cover & Percentage of sky from horizon to horizon covered by cloud \\
\hline Temperature & $\begin{array}{l}\text { Ambient air temperature measured within the grass at } \\
\text { approximately } 20 \mathrm{~cm} \text { from the ground }\end{array}$ \\
\hline \multicolumn{2}{|l|}{ Model Behaviours } \\
\hline Model Mating Status & $\begin{array}{l}\text { How the models were found at time of being caught. Single: } \\
\text { found alone, Tandem: found in tandem with a partner, } \\
\text { Copula: found in a copulation wheel }\end{array}$ \\
\hline Wing Flutters & The model flutters its wings at high speed. \\
\hline Abdomen Curls & The model curls its abdomen underneath towards its thorax \\
\hline \multicolumn{2}{|l|}{ Methodology } \\
\hline Presentation Order & $\begin{array}{l}\text { The order the model was presented in, from the first } \\
\text { presentation to the response male to the sixth presentation }\end{array}$ \\
\hline Location & Location of testing: LeRoi or Barb's Marsh \\
\hline $\begin{array}{l}\text { Response Male } \\
\text { Behaviour }\end{array}$ & $\begin{array}{l}\text { The response of the male either sexual or non sexual } \\
\text { responses }\end{array}$ \\
\hline Time & Time the male took to respond to the model \\
\hline Date & Date and Time of presentation \\
\hline Morph & The sex and morph of the model \\
\hline Block & Numbered by block of models and males \\
\hline Male & Each response male's identifying number \\
\hline
\end{tabular}




\subsection{Results}

\section{$\underline{\text { Assessment of Methodology }}$}

To assess the impact of repeated trials on the same individual male we looked at the mean frequency of sexual behaviour over the 6 presentations in all blocks. Previous studies have shown a population level average of $0.451 \pm 0.018$ tandem attempts by all males (Ting et al. 2009). We see that our males had an equal average number of tandem attempts at onset $(0.45 \pm 0.036)$ but they reduced their attempts to form tandems between the first presented model and the final presentation (Kruskal-Wallis $\mathrm{H}=21.658, \mathrm{df}=5$, $\mathrm{p}=0.0006$; Figure 3-1). As models were presented in blocks with all possible randomized orders, each model type experienced the same reduction in tandem attempts relative to the other model types (Table 3-3). 


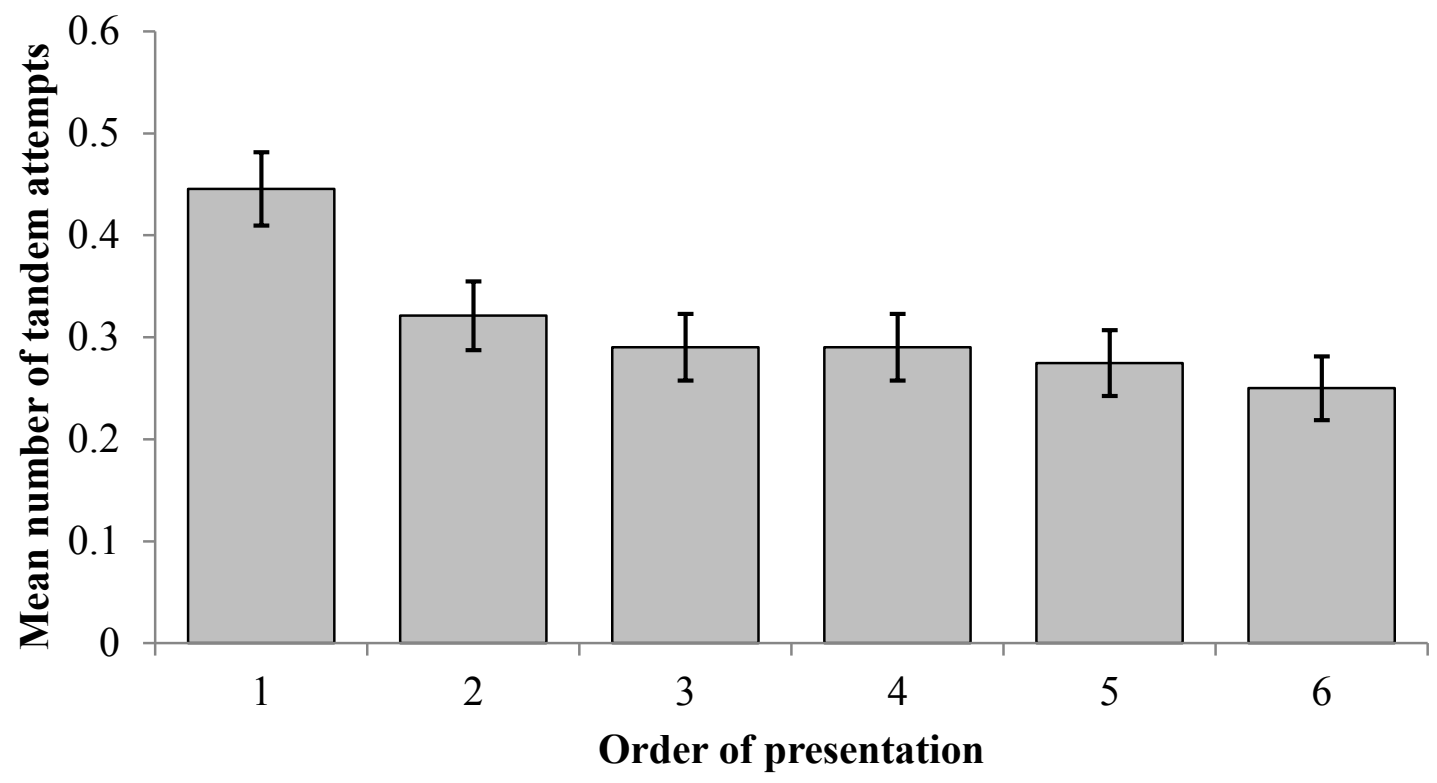

Figure 3-1. Mean number of tandem attempts (mean \pm SE) over time (presentation order) for male $N$. irene for all models. Male response with the first presentation is consistent with previous findings. However, male response significantly decreases with multiple presentations (Kruskal-Wallis $\mathrm{H}=\mathbf{2 1 . 6 5 8}, \mathrm{df}=5, \mathrm{p}<\mathbf{0 . 0 0 1})$. 
Table 3-3. Mean number of tandem attempts ( \pm SE) on andromorphs $(A)$, gynomorphs (G) and males (M) over presentation order for male $N$. irene. All models experience a decrease in sexual activity at the same rate.

\begin{tabular}{|l|l|l|l|}
\hline Order & A & G & M \\
\hline 1 & $0.47 \pm 0.063$ & $0.45 \pm 0.062$ & $0.42 \pm 0.062$ \\
\hline 2 & $0.33 \pm 0.059$ & $0.38 \pm 0.061$ & $0.27 \pm 0.056$ \\
\hline 3 & $0.31 \pm 0.058$ & $0.27 \pm 0.056$ & $0.28 \pm 0.057$ \\
\hline 4 & $0.31 \pm 0.058$ & $0.28 \pm 0.056$ & $0.27 \pm 0.056$ \\
\hline 5 & $0.34 \pm 0.060$ & $0.30 \pm 0.058$ & $0.17 \pm 0.048$ \\
\hline 6 & $0.25 \pm 0.055$ & $0.22 \pm 0.052$ & $0.28 \pm 0.057$ \\
\hline
\end{tabular}




\section{$\underline{\text { Male response behaviour }}$}

A total of 39 blocks (1404 presentations in total) were performed in the field for both locations. After discarding blocks that were incomplete, with damaged individuals or other errors, 32 blocks or 1151 observations were used for analysis.

In the previous chapter male $N$. irene had the highest number of tandem attempts with gynomorphs but would attempt tandems with all other model types consistent with previous studies of $N$. irene male preferences. Specifically $N$. irene males significantly chose female morphs over other potential mates offered. We first looked at overall mate preferences by comparing the mean number of tandem attempts on all model types between locations. We found that $N$. irene males do not have differences in preferences between locations (Kruskal-Wallis $\mathrm{H}=3.58, \mathrm{df}=5, \mathrm{p}=0.61$, Figure 2-2). We then checked for preferences within locations and found that male $N$. irene do not have a preference for any particular model at either location at a population level (Alexandria: $\mathrm{H}=3.11, \mathrm{df}=2$, $\mathrm{p}=0.21$ : LeRoi: $\mathrm{H}=0.21, \mathrm{df}=2, \mathrm{p}=0.90$ : Figure 2-2). Previous studies at LeRoi Marsh had equivalent mating rate between models (Ting et al. 2009). These results allow us to combine data between both locations for modelling. 


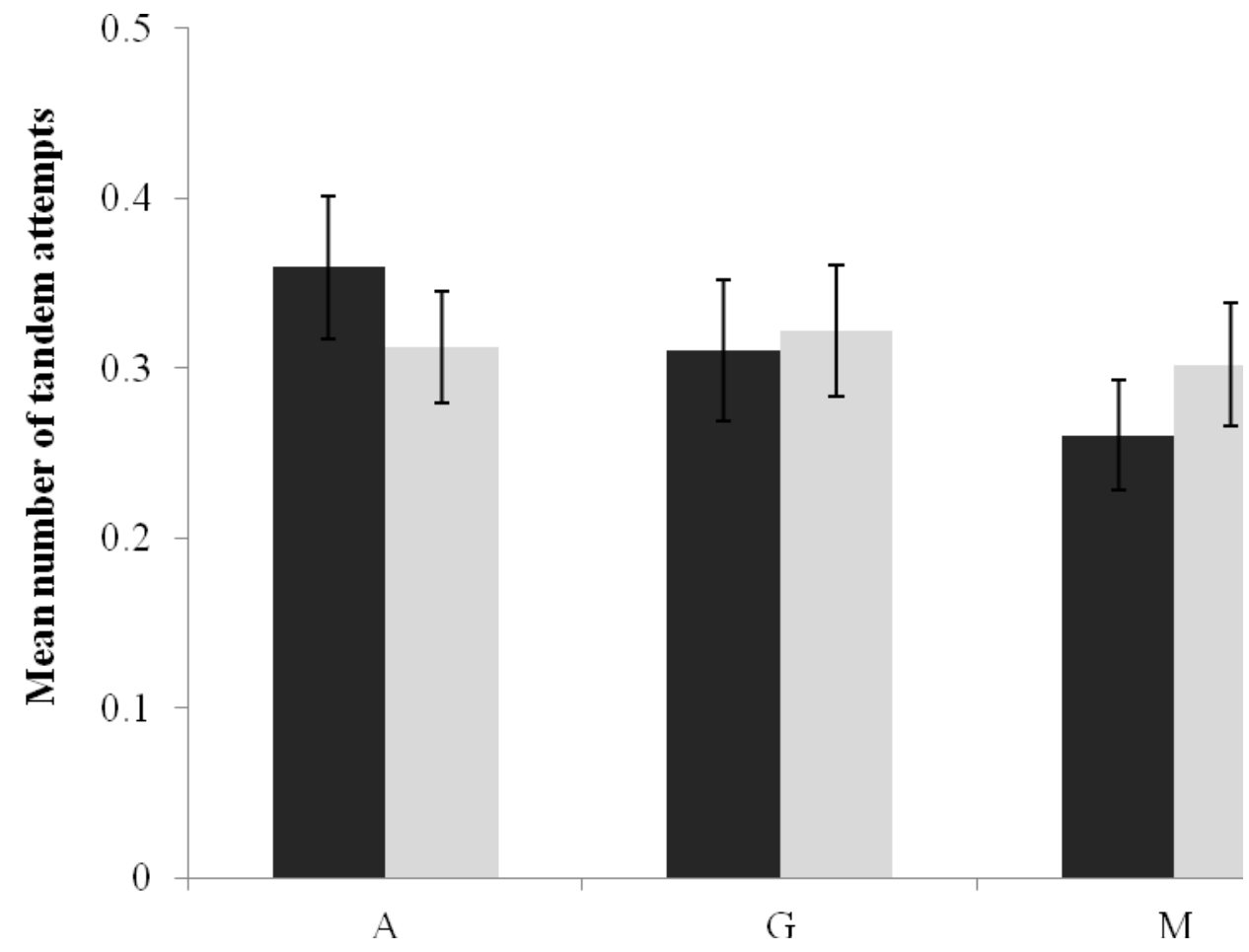

Figure 3-2. Comparison of population level preference for $A=$ andromorphs, $G=$ gynomorphs and M=male models by $N$. irene males at Alexandria (Black) and LeRoi Marsh (Grey). No differences in preference were found between location (Kruskal-Wallis $\mathrm{H}=\mathbf{3 . 5 8}, \mathrm{df}=\mathbf{5}, \mathrm{p}=\mathbf{0 . 6 1}$ ) or model (Alexandria: $\mathrm{H}=3.11, \mathrm{df}=2, \mathrm{p}=\mathbf{0 . 2 1}$ : LeRoi: $\mathrm{H}=\mathbf{0 . 2 1}, \mathrm{df}=\mathbf{2}, \mathrm{p}=\mathbf{0 . 9 0}$ ). 
We sought to test if individual male $N$. irene mate choices were consistent with this population level preference or if males had clear preferences for one morph. At a population level, at both locations all the models invoked similar reactions by males. To test the MM and LMR hypotheses we need to look at individual male preferences for models. In all the best models, the individual male ('male interaction') does not play a significant role in shaping the dependent variable (sexual behaviour) (Table 3-4). Thus, there is no evidence of inter-male variability in preference. This result is predicted by the MM hypothesis (but contrary to the LMR hypothesis).

\section{Environmental variables}

Overall, the best model to explain variation in male tandem attempts included weather effects, specifically wind speed (Table 3-4). LeRoi Marsh had higher wind speeds than at Alexandria, and males seemed to respond at a higher rate on windy days, although there was no difference in male preferences between models at these two locations $(\mathrm{H}=3.578$, $\mathrm{df}=5, \mathrm{p}=0.612$ ). Other weather variables including time of day, cloud cover and air temperature did not impact the sexual behaviour of the response males during the study (all $\mathrm{p}>0.05)$. 
Table 3-4. Summary table of modelling. Greater numbers for evidence ratio indicates more support for the model. Location, order, model type, model type status, abdomen curl and block seem to be predictors of sexual behaviour by males. Appendix A includes coding for full and null models.

\begin{tabular}{|c|c|c|c|c|c|}
\hline Models & logLik & AIC & $\Delta \mathrm{AIC}$ & wAIC & Evidence Ratio \\
\hline $\begin{array}{l}\text { Location, order, wind, model } \\
\text { type, model type by location, } \\
\text { model type status, abdomen curl, } \\
\text { block }\end{array}$ & -407.3 & 836.5 & 0.0 & 0.26 & 34.81 \\
\hline $\begin{array}{l}\text { Location, order, wind, model type } \\
\text { by location, model type status, } \\
\text { abdomen curl, block }\end{array}$ & -407.3 & 836.5 & 0.0 & 0.26 & 34.81 \\
\hline $\begin{array}{l}\text { Location, wind, model type, model } \\
\text { type by location, model type status, } \\
\text { abdomen curl, block }\end{array}$ & -408.6 & 837.2 & 0.7 & 0.18 & 24.53 \\
\hline $\begin{array}{l}\text { Order, wind, model type status, } \\
\text { abdomen curl, block }\end{array}$ & -412.9 & 837.7 & 1.2 & 0.14 & 19.11 \\
\hline $\begin{array}{l}\text { Location, model type, model type } \\
\text { by location, model type status, } \\
\text { abdomen curl, block }\end{array}$ & -410 & 838.1 & 1.6 & 0.12 & 15.64 \\
\hline $\begin{array}{l}\text { Location, order, wind, model } \\
\text { type, model type by location, } \\
\text { model type status, abdomen curl, } \\
\text { male interactions, block }\end{array}$ & -407 & 840 & 3.5 & 0.04 & 6.05 \\
\hline Full & -406 & 843.9 & 7.1 & 0.007 & 1.00 \\
\hline Null & N/A & 927.0 & 90.5 & $\sim 0$ & 0.00 \\
\hline
\end{tabular}




\section{$\underline{\text { Model mating status }}$}

Since females that are ready to mate may indicate this to available males thus influencing male sexual response it is important to know the status of the model presented to the response males. However, it is not possible to know the actual reproductive status of the models that were used in the study as prior behaviour was not observed. Instead the state the models were found in when netted (single, tandem or in copula) was noted. Inclusion of status into model fitting indicates that model status does have an effect on the response male's behaviour (Table 3-4). In order to see the effect of model status on mean number of tandem attempts by males we compared the tandem activity between these three groups using Kruskal Wallis test $(\mathrm{H}=1.72, \mathrm{df}=2, \mathrm{p}=0.42)$. There was no significant difference in tandem activity between models caught singly, in tandem or in a copulation wheel (Figure 3-3). Although there seems to be indications that models caught in copulation wheels have higher median rates of tandem attempts (Figure 3-3) the sample size of this group is very limited $(n=3)$ and has low statistical power. 


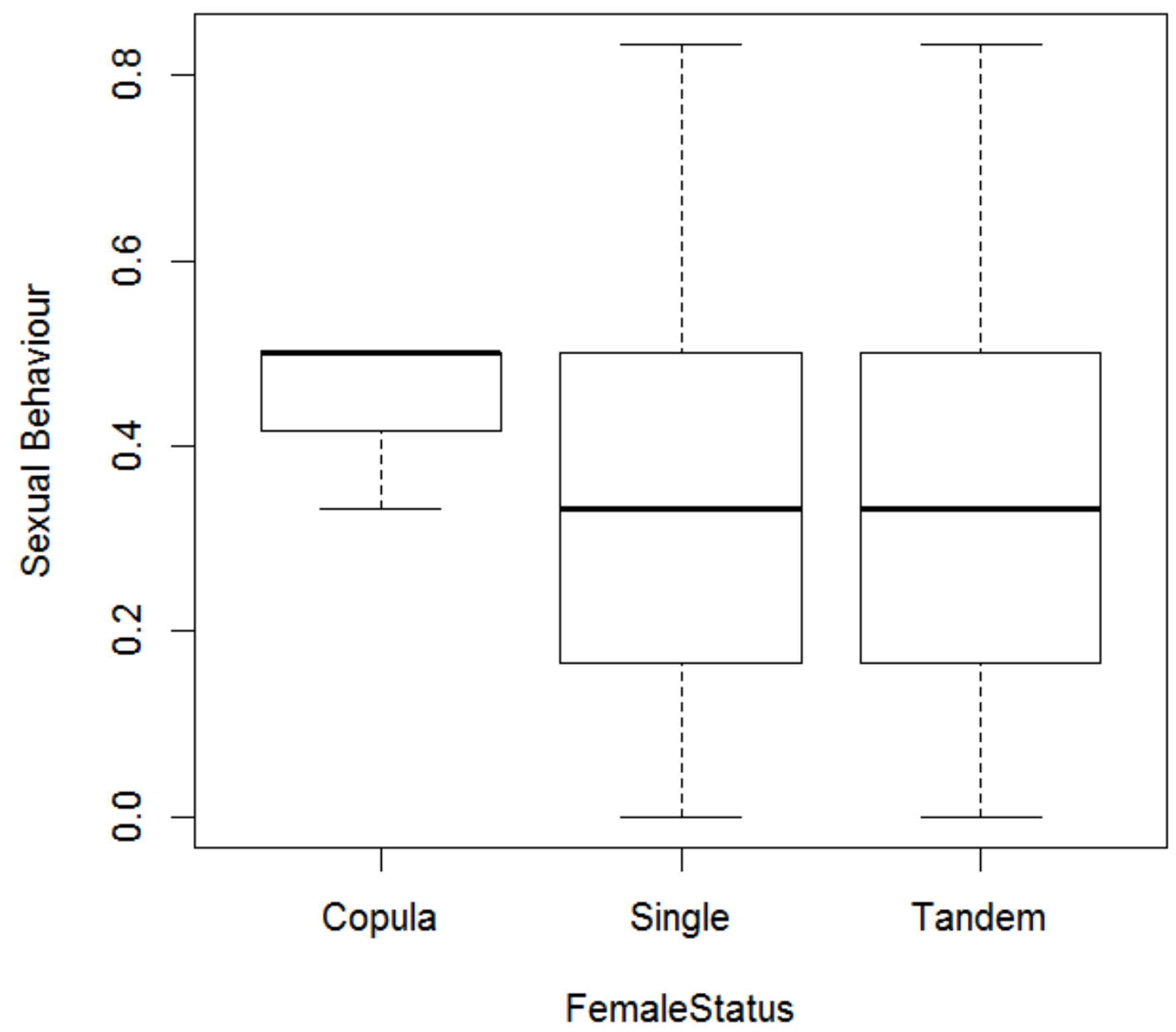

Figure 3-3. Response male sexual behaviour (average number of tandem attempts) between models caught in copula $(n=3)$, individually (Single, $n=50)$ or in a tandem $(n=62)$ with another individual. 
Models show that female behaviour was quite important to the sexual behaviour in the response male. Abdomen curls, when the female curls her abdomen under her body, has been noted in the literature as an important refusal behaviour for females (Ting et al. 2009). In this study models displayed abdomen curls in 52 out of 244 presentations. Overall, when models did not display abdomen curls $32 \%$ of the males had a sexual response towards the model. However when the model displayed abdomen curls, the males responded sexually in only $12 \%$ of cases. Refusal behaviour in the form of abdomen curls causes a significant reduction in the number of tandem attempts by response males $(\mathrm{H}=262.0, \mathrm{df}=5, \mathrm{p}<0.001$, Figure 3-4). Although not significant, with equal numbers of models displaying abdomen curls $\left(\mathrm{n}_{\mathrm{A}}=21, \mathrm{n}_{\mathrm{G}}=22, \mathrm{n}_{\mathrm{M}}=22\right)$ andromorphs received the least number of tandem attempts (Figure 3-4). 


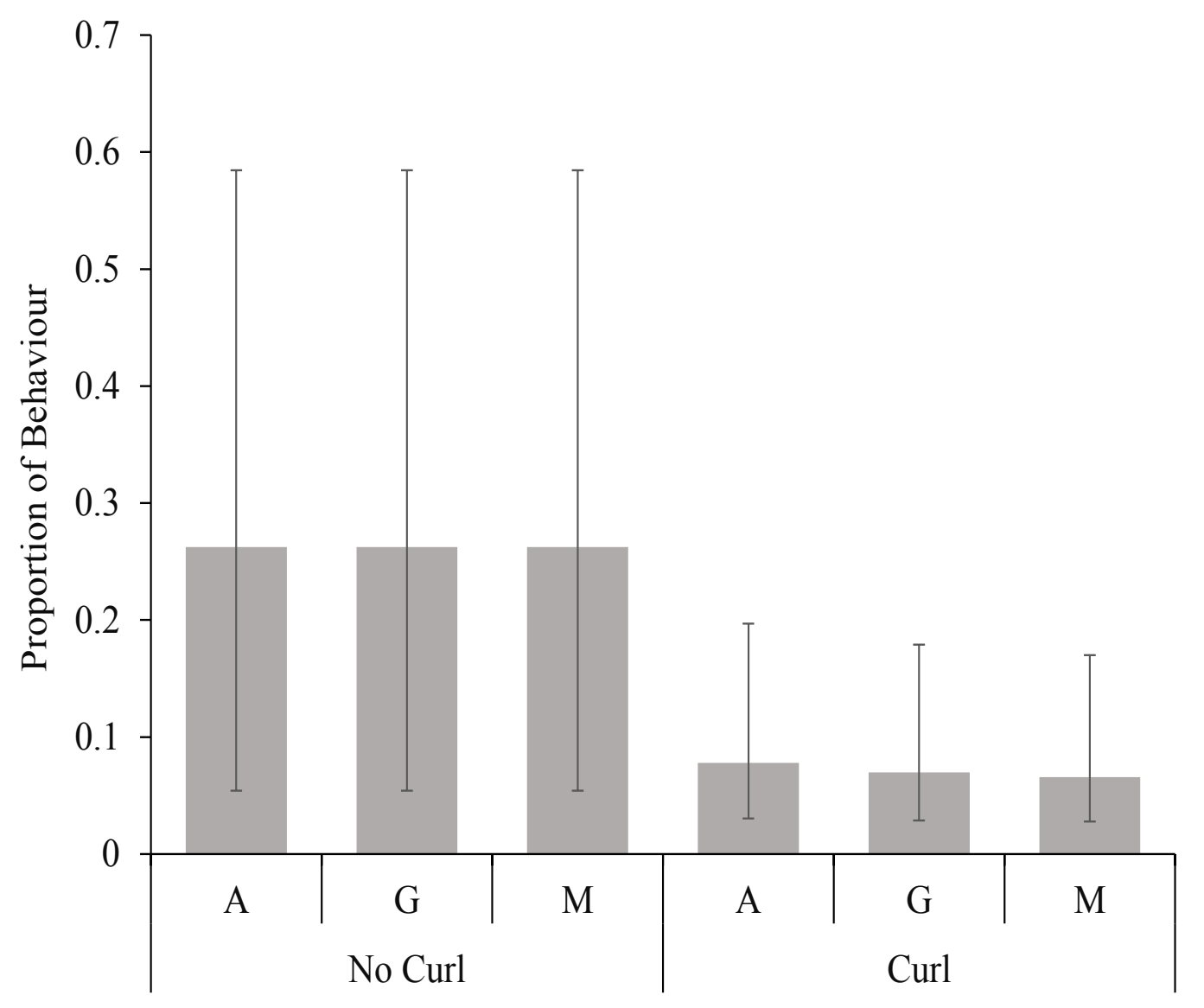

Figure 3-4. Comparison of proportion of abdomen curls (or not) for andromorphs (A), gynomorphs (G) and males (M) $( \pm 95 \%$ CI) out of all recorded trials $(n=244)$. Abdomen curls were recorded in 52 (out of 244) presentations. Equal numbers of abdomen curls were recorded for all 3 morphs. 


\subsection{Discussion}

Sexual selection is predicted to be a driver for the maintenance of sex limited

polymorphisms. Although male limited polymorphisms are associated with alternative mating strategies female limited polymorphisms are more complex. There are a number of explanations for the evolution and maintenance in females ranging from Batesian mimicry, to alternative mating strategies, to avoidance of male harassment.

Here I have attempted to test the predictions of two hypotheses that explain the maintenance of female polymorphism in terms of male mate choice. These theories differ in that LMR states that with successful mating individual males should prefer one morph over other morphs while MM theory predicts that individual males will choose mates whom they recognize as female. My results indicate that reproductively active males will attempt to mate with approximately the same probability to all models presented to them, regardless of morph, sex, or previous encounters with other models (Figure 3-2, Table 3-4). This is surprising in that previous work has shown that this species has a preference for gynomorphs over other models when gynomorphs are predominant as in our sites (Robertson 1985, Cordero Rivera 1998, Van Gossum et al. 2007, Ting et al. 2009). However, previous population level studies at these exact locations indicate that males do not choose one morph over the other (Ting et al. 2009). With this in mind, our results indicate that individual level preferences by males are the same as population level preferences. In this case the MM hypothesis still predicts that individual males will not be specific to one morph over another over multiple encounters, while the LMR theory states that an individual male would be likely to choose only one morph to mate with. Thus, our results are inconsistent with the LMR hypothesis. 
Male mate harassment is predicted to be a driver of the maintenance of the andromorph form in $N$. irene. In this population with an equivalent number of tandem attempts for both models male mating harassment seems to be the same for both female morphs. However, both hypotheses are based on negative frequency dependence in that the benefit goes to the rarer morph. In the MM hypothesis the benefit of andromorphs requires rarity of andromorphs (mimics) relative to males (models)(Sherratt 2001). These locations had high densities of andromorphs (Alexandria: 29\%, Otter: 39.9\%, at peak). In these locations male mimicry may not confer an advantage onto andromorphs.

In addition, our results found that males will readily attempt to mate with other males at the same rate as its own andromorph (Figure 3-2). Other studies have had similar results with males attempting matings with other males (Forbes et al. 1997, Fincke et al. 2007, Ting et al. 2009). Most importantly, Ting et al. (2009) found an increase in mating rate on males with an increase in andromorph frequency in the population. With a higher frequency of andromorphs males experience more encounters, but instead of becoming more specialized to andromorph signals, they have a greater frequency of signal detection errors ('false alarms'). Male detection ability is based on their capability to cue to the model's signalling. Our results indicate that males are easily misled by the signals between andromorphs and males. This suggests that andromorphs are very good mimics of males.

Females can have morphological or behavioural signals to cue males on their identity and receptivity to mate. Stick presentations allow for some behaviours from models; in particular, models are able to perform behaviours such as wing flutters and abdomen curls. Our work found that all models had the tendency to show abdomen curls 
at the same rate, and males were less like to mate with models displaying abdomen curls (Figure 3-4). Previous work has shown similar results, that abdomen curls are an effective refusal behaviour to avoid male harassment (Ting et al. 2009) in N. irene. Abdomen curls could be effective refusal cues for two reasons. First, females could be indicating their lack of eggs through having the ability to bend the 'empty' abdomen and being able to fly a fast erratic flight due to lack of weight (Forbes 2013). Secondly, odonates are visual animals and have been noted to have a strong response to motion (Olberg et al. 2000, Greenfield 2002). Odonate visual neurons have a greater sensitivity to objects that have a shorter length in the direction of motion, then to a greater length (Olberg 1981). Females displaying abdomen curls are creating a body position and motion that would have an increased signal response in male visual neurons compared to non-cueing females. Interestingly, in this study males were less likely to attempt tandems with andromorphs displaying abdomen curls over all other models (gynomorphs and males). Since males more readily recognize gynomorphs as female, that andromorphs are attacked less frequently is not surprising. However, when both males and andromorphs use abdomen curls at the same rate, yet andromorphs are approached less often than males is unusual. In the field males have not been observed to use abdomen curls as a refusal behaviour as they usually approach other males head on in an aggressive manner, which would discourage and cue other males to their identity. Andromorphs have also been noted to use these male-like cues (Van Gossum et al. 2001a, Sirot et al. 2003). When attached to sticks males are unable to use the cues they would normally use so may resort to curling their abdomen. This abdomen curling may be different or of lower quality than the abdomen cue used by females to advertise their egg capacity and cause 
response males to misinterpret the cue relative to a female's signal.

Populations of $N$. irene are female-limited systems where the goal of males are to have a high number of matings relative to females. As a consequence, this unavailability of mates has produced high levels of male harassment and possibly, a system where males need to attempt to mate with all potential mates and so will tolerate large variation in signals. We would predict the cost to the male of attempting to mate with males is very low compared to the cost of missing a potential mate. As stated before males can use tactile cues to identify females (Uhia and Rivera 2005, McPeek et al. 2011) and additionally cannot form successful tandems with other males. These methods may more clearly signal available mates to males than visual signals and cost the male very little in time and effort. A large proportion of males may not mate in their lifetime (Banks and Thompson 1985, Fincke 1997) suggesting a high cost of missing the opportunity to mate. This lack of cost for false alarms in relation to a high cost of missed opportunities may give rise to this male tolerance for signal detection errors between andromorphs and males. At both study locations, previous population level presentation studies have shown that males do not have a preference for either female morph (Ting 2009) as found in the current study. The composition of these populations range from 20 to $40 \%$ andromorphs and the converse in gynomorphs within a season. Since there can be a large variation in population composition within seasons and between years (Svensson et al. 2005) and if males do not have a preference for either morph at these locations why would there be fewer andromorphs than gynomorphs in these populations? This suggests that other influences are affecting the frequencies of female morphs in the environment. Andromorphs and gynomorphs differ in more than colouration. Previous studies have 
found differences in size, behaviour, conspicuousness, and life history (Van Gossum 2004, Joop et al. 2006b, Bots et al. 2009c, Cooper 2010, Takahashi and Watanabe 2010b) between female morphs. These differences between the female morphs could influence the rate of encounters, or reduce harassment and mating rates with males and so influence the maintenance of female limited polymorphisms. Despite the fact that males choose to mate with andromorphs at the same rate as gynomorphs when available, the percentage of andromorphs in the population is much lower. This suggests that behavioural or life history differences are especially important in the case of andromorphs. These differences could be masked by the method of stick presentations which may remove some female behaviours and causes females to be more conspicuous to males during these trials.

The results suggest that males experience signal detection errors when selecting a mate, and when using stick presentations males are generalists displaying individual preferences for mates in the same manner as population level preferences. These results agree with the male mimicry hypothesis. However, stick presentation methodology prevents more natural avoidance behaviours from occurring and does not take life history differences between female morphs into account. Previous work compared stick presentations to more natural caged environment where females could display a larger repertoire of behaviours found similar results in both methodologies (Ting et al. 2009). However, both methodologies could still make models much more conspicuous to males and influence their mating rate compared to natural situations. This missing information could be important in explaining the evolution and maintenance of female polymorphisms. 


\section{Chapter: Discussion}

Visual polymorphisms are an excellent system to use for the study of evolutionary processes that regulate variation in nature. Sexual selection is an important process in the evolution and maintenance of sex limited polymorphisms. A large part of sexual selection is the conflict between male and female reproductive strategies. Female limited polymorphism is common to odonates and was used as a system to investigate the impact of mate discrimination and recognition on reproductive interference and character displacement, and to evaluate two main hypotheses that explain the maintenance of female limited polymorphisms in odonates.

In the first chapter I briefly summarized the role of signal detection theory in explaining the detection of mates and the exploitation of noise. I used this framework to describe how problems with detection can create interspecific interactions. I reviewed how these interactions could cause character displacement in similar sympatric species. Character displacement has been shown in only a few species and it is not yet understood how widespread this mechanism is.

I then went on to review the literature on sexual selection, the formation of polymorphisms, and specifically focused on visual sex limited polymorphisms in odonates. I introduced the idea of male mate choice in odonates and costs of reproduction on males. I then reviewed the two main theories on the maintenance of female polymorphisms in damselflies - Learned Mate Recognition (LMR) and Male Mimicry (MM) hypotheses. These theories have been extensively studied. However, most studies investigate mate recognition at population level rather than at an individual level. This shortfall is significant because these two theories predict the choices of 
individuals, not populations as a whole.

In the second chapter I used field studies combined with previously published data to look at mate recognition and preferences in two sympatric sister species Nehalennia irene and Nehalennia gracilis. Our hypothesis was that $N$. irene should have a lower signal threshold and increased amount of mating attempts on conspecific males and heterospecifics compared to $N$. gracilis. This was expected due to a higher probability of encountering their own mate and less need for female specific detection. From the same argument $N$. gracilis was expected to be choosy and have higher signal threshold due to a high probability of encountering heterospecifics. Our study found that $N$. irene males preferred to mate with gynomorphs but did not discriminate between blueblack morphs as predicted. Against our prediction, $N$. gracilis equally attempted to mate with heterospecifics and conspecifics. These results suggest that i) $N$. irene and $N$. gracilis do not have robust detection ability between blue-black models as they are equally likely to attempt tandems with all blue-black models; ii) the cost of missed mating opportunities to mate is greater than the cost of false alarms when you are rare; iii) males with experience with blue-black models do not have greater discriminatory ability than males without experience; and iv) N. gracilis is likely experiencing reproductive interference from $N$. irene males.

In addition, since odonates are visual animals that have been shown to use abdominal and thorax colours and patterns as mate cues (Bick and Bick 1965, Van Gossum et al. 2011), I looked at displacement of thorax colour. I scanned the thoraxes of models at 2400 dpi and used an imaging program (ImageJ) to make a RGB colour analysis of sections of the thorax. Both principle component analysis (PCA) and 
MANOVA indicate there is no difference in RGB colour of thoraxes for all blue-black morphs between sympatric and allopatric sites. Although my results failed to support character displacement of colour, females could be using a variety of other tactics to reduce reproductive interference or have displacement of other morphological or behavioural characters not studied presently. Interestingly, there are differences in colour between male $N$. irene and $N$. gracilis with $N$. irene having more yellow tones and $N$. gracilis appearing bluer. This means that females could distinguish between males on the basis of colour. It would be interesting to find out if females choose to place themselves in proximity to correct mates.

In Chapter 3 I compared the predictions of the MM and LMR hypothesis on individual male mate choices by presenting individual males with 2 gynomorph, 2 andromorph and 2 male models. The MM hypothesis predicts that individual males will not be specific to one morph over another over multiple encounters while LMR predicts that individual males will choose only one morph to mate with after successful mating experience. Our results indicate that males will try to mate, with the same probability, with any model presented to them regardless of morph, sex, or experience with a previous morph. These results are inconsistent with the LMR hypothesis. Overall, males do not distinguish nor show preferences for specific morphs. Interestingly, females have morphological or behavioural signals to let males know their identity and receptivity to mate such as abdomen curls.

Research into odonate visual systems is ongoing. Currently we know the visual range of odonates goes past human vision into UV wavelengths (Bybee et al. 2012). Fincke et al. (2007) found the largest range of colour differences in Enallagma ebium in 
the UV component of thorax reflectance spectra. Although $N$. irene males and andromorphs and $N$. gracilis females appear identical to us, they may appear much differently to themselves. More research into odonate colour vision will help our understanding of colour signals and decision making between these species.

My results suggest that the cost of missing a mating opportunity is greater than the cost of attempting tandems with heterospecifics and conspecific males. If this is so, why is the average mating rate for males so low? In two seasons of studies at the same location and multiple studies at different locations, males seem to attempt mating a maximum of $65 \%$ of the time, and usually at a rate much less than this (Ting et al. 2009). Occasionally there are males that refuse all matings (Chapter 2). There are several reasons males could refuse mating opportunities. Males could be unable to mate due to age, low energy reserves, a lack of sperm because of previous matings, disease or parasitism that affect their condition. Research on why males refuse matings could help us understand the cost of mating to males.

In conclusion my results indicate that males experience signal detection errors when selecting a mate and are motivated by a lack of mating opportunities to not pass up any encounter. This result is in line with reports of coercive mating and male harassment by odonate males. Still, females have strategies that allow them to optimize their mating rate. My methodology of stick presentations may mask these strategies between andromorphs and gynomorphs and their males. Since my results were unable to fully support either of the hypotheses, and behavioural differences between morphs seems important, more investigations into life history differences between these morphs are warranted. In addition, recent research by Cooper (2010) has found an environmental 
explanation for colour polymorphisms in damselflies. The understanding of how evolutionary processes maintain polymorphisms may involve a balance between environment, biology and sexual selection. 


\section{Appendices}

\section{Appendix A}

\section{A.1 Sample of R-code from Chapter 3}

Full Model:

$\operatorname{lmfull}<-$

lmer(Code $\sim$ Location + Order+Wind+Cloud+Temperature+StatCode+typemode+Location: typemode $+(1 \mid$ male:tally:Location $)+(1 \mid$ male:tally:Location:typemode $)+(1 \mid$ tally:Location $)+$ Abdomen_Curl+Wing_Flutter,family=binomial)

Null Model:

null.model $<-\operatorname{lm}($ Code $\sim$,data $=a)$

AIC(null.model)

Model without non-significant variables (Cloud, Temperature, Wing_Flutter, Block, Identifier)

$\operatorname{lm} 2<-$

lmer(Code $\sim$ Location+Order+Wind+typemode+Location:typemode+StatCode+Abdomen _Curl+(1|male:tally:Location $)+(1 \mid$ male:tally:Location:typemode $)+(1 \mid$ tally:Location $)$, famil $\mathrm{y}=$ binomial) 


\section{A.2 Codes}

Location: the study site

Order: presentation order of the model (from 1 to 6 )

Wind: wind speed

Cloud: cloud cover $(\%)$

StatCode: 'reproductive' status of the model when caught (single, tandem, in copula)

Typemode: type of model

Abdomen_Curl: whether the model abdomen curled during presentation

Wing_Flutter: whether the model made wing flutters during presentation 


\section{Bibliography}

Allen, J. A., and B. Clarke. 1968. Evidence for apostatic selection by wild passerines. Nature 220:501-502.

Allen, J. A. 1998. The influence of density on frequency-dependent selection by wild birds feeding on artificial prey. Proceedings of the Royal Society B-Biological Sciences 265:1031-1035.

Andres, J. A., R. A. Sanchez-Guillen, and A. C. Rivera. 2000. Molecular evidence for selection on female color polymorphism in the damselfly Ischnura graellsii. Evolution 54:2156-2161.

Arnqvist, G., and T. Nilsson. 2000. The evolution of polyandry: multiple mating and female fitness in insects. Animal Behaviour 60:145-164.

Arnqvist, G., and L. Rowe. 2005. Sexual conflict. Princeton University Press.

Arntzen, J. W. 1999. Sexual selection and male mate choice in the common toad, Bufo bufo. Ethology Ecology \& Evolution 11:407-414.

Banks, M. J., and D. J. Thompson. 1985. Lifetime mating success in the damselfly Coenagrion puella. Animal Behaviour 33:1175-1183.

Baranwal, V. K., V. Mikkilineni, U. B. Zehr, A. K. Tyagi, and S. Kapoor. 2012.

Heterosis: emerging ideas about hybrid vigour. Journal of Experimental Botany 63:63096314.

Bel-Venner, M. C., S. Dray, D. Allaine, F. Menu, and S. Venner. 2008. Unexpected male choosiness for mates in a spider. Proceedings of the Royal Society B-Biological Sciences 275:77-82.

Bergsten, J., A. Toyra, and A. N. Nilsson. 2001. Intraspecific variation and intersexual correlation in secondary sexual characters of three diving beetles (Coleoptera : Dytiscidae). Biological Journal of the Linnean Society 73:221-232.

Berniker, L., and C. Weirauch. 2012. World biogeography and the evolution of polychromatism: evidence from the bee assassin genus Apiomerus (Heteroptera: Reduviidae: Harpactorinae). Systematic Entomology 37:32-54. Beukema, J. J. 2004. Recognition of conspecific females by males of Calopteryx haemorrhoidalis (Vander Linden) (Zygoptera : Calopterygidae). Odonatologica 33:147156.

Bick, G. H., and J. C. Bick. 1965. Color variation and significance of color in reproduction in the damselfly, Argia apicalis (Say) (Zygoptera: Coenagriidae). The Canadian Entomologist 97:32-41.

Bonansea, M., and M. Vaira. 2012. Geographic and intrapopulational variation in colour and patterns of an aposematic toad, Melanophryniscus rubriventris (Amphibia, Anura, Bufonidae). Amphibia-Reptilia 33:11-24.

Bonduriansky, R. 2001. The evolution of male mate choice in insects: a synthesis of ideas and evidence. Biological Reviews 76:305-339.

Bots, J., C. J. Breuker, A. Van Kerkhove, S. Van Dongen, L. De Bruyn, and H. Van Gossum. 2009a. Variation in flight morphology in a female polymorphic damselfly: intraspecific, intrasexual, and seasonal differences. Canadian Journal of Zoology-Revue Canadienne De Zoologie 87:86-94.

Bots, J., L. De Bruyn, S. Van Dongen, R. Smolders, and H. Van Gossum. 2009b. Female polymorphism, condition differences, and variation in male harassment and ambient 
temperature. Biological Journal of the Linnean Society 97:545-554.

Bots, J., S. Van Dongen, T. Adriaens, H. J. Dumont, R. Stoks, and H. Van Gossum. 2009c. Female morphs of a colour polymorphic damselfly differ in developmental instability and fecundity. Animal Biology 59:41-54.

Briscoe, A. D., and L. Chittka. 2001. The evolution of color vision in insects. Annual Review of Entomology 46:471-510.

Bybee, S. M., K. K. Johnson, E. J. Gering, M. F. Whiting, and K. A. Crandall. 2012. All the better to see you with: a review of odonate color vision with transcriptomic insight into the odonate eye. Organisms Diversity \& Evolution 12:241-250.

Calsbeek, R., and R. M. Cox. 2012. An experimental test of the role of predators in the maintenance of a genetically based polymorphism. Journal of Evolutionary Biology 25:2091-2101.

Candolin, U., T. Salesto, and M. Evers. 2007. Changed environmental conditions weaken sexual selection in sticklebacks. Journal of Evolutionary Biology 20:233-239.

Celestino, L. 2006. Range maps of Odonata. Green Mountain College.

Charles, M. S., and J .V. Robinson. 1981. A scanning electron microscope study of the blue reflecting particles in Enallagma civile (Hagen)(Zygoptera: Coenagrionidae). Odontologica 10:219 -222.

Clutton-Brock, T. 2007. Sexual selection in males and females. Science 318:1882-1885. Cooper, I. A. 2010. Ecology of sexual dimorphism and clinal variation of coloration in a damselfly. American Naturalist 176:566-572.

Cordero, A. 1990. The inhertiance of female polymorphism in the damselfly Ischnuragraellsii (Rambur) (Odonata, Coengrionidae). Heredity 64:341-346.

Cordero Rivera, A. 1998. Mating opportunities and mating costs are reduced in an androchrome female Ishnura elegans. Animal Behaviour 55:185-197.

Córdoba-Aguilar, A (ed). 2008. Dragonflies and damselflies: model organisms for ecological and evolutionary research. University of Oxford Press, Oxford.

Cordoba-Aguilar, A., and D. M. Gonzalez-Tokman. 2011. Male harassment and female energetics in the territorial damselfly Hetaerina americana (Fabricus)(Zygoptera: Calopterygidae). Odonatologica 40:1-15.

Dijkstra, K.-D. B., A. C. Rivera, and J. A. Andrés. 2001. Repeated predation of Odonata by the hornet Vespa crabro (Hymenoptera: Vespidae). International Journal of

Odonatology 4:17-21.

Dittrich, W., F. Gilbert, P. Green, P. Mcgregor, and D. Grewcock. 1993. Imperfect mimicry: a pigeon's perspective. Proceedings: Biological Sciences 251:195-200.

Dorn, A., E. Ng'oma, K. Janko, K. Reichwald, M. Platzer, A. Cellerino, and M. Reichard. 2011. Phylogeny, genetic variability and colour polymorphism of an emerging animal model: The short-lived annual Nothobranchius fishes from southern Mozambique.

61:739-749.

Fincke, O. M. 1997. Conflict resolution in the Odonata: implications for understanding female mating patterns and female choice. Biological Journal of the Linnean Society 60:201-220.

Fincke, O. M. 2004. Polymorphic signals of harassed female odonates and the males that learn them support a novel frequency-dependent model. Animal Behaviour 67:833-845.

Fincke, O. M., A. Fargevieille, and T. D. Schultz. 2007. Lack of innate preference for morph and species identity in mate-searching Enallagma damselflies. Behavioral Ecology 
and Sociobiology 61:1121-1131.

Fincke, O. M., R. Jödicke, D. R. Paulson, and T. D. Schultz. 2005. The evolution and frequency of female color morphs in Holarctic Odonata: why are male-like females typically the minority? International Journal of Odonatology 8:183-212.

Forbes, M. R. 1991a. Ectoparasites and mating success of male Enallagma ebrium damselflies (Odonata: Coenagrionidae). Oikos 60:336-342.

Forbes, M. R. 1991b. Female morphs of the damselfly Enallagma boreale Selys (Odonata: Coenagrionidae): a benefit for androchromatypes. Canadian Journal of Zoology 69:1969-1970.

Forbes, M. R. 2013. personal communication.

Forbes, M. R., G. Schalk, J. G. Miller, and J. M. L. Richardson. 1997. Male-female morph interactions in the damselfly Nehalennia irene (Hagen). Canadian Journal of Zoology-Revue Canadienne De Zoologie 75:253-260.

Ford, E. B. 1957. Polymorphism in plants, animals and man. Nature 180:1315-1319.

Futahashi, R., R., Kurita, H. Mano, and T. Fukatsu, T. 2012. Redox alters yellow dragonflies into red. Proceedings of the National Academy of Sciences of the United States of America 109:12626-12631.

Gorb, S. 1998. Visual cues in mate recognition by males of the damselfly Coenagrion puella. Journal of Insect Behavior 11:73-92.

Gosden, T. P., and E. I. Svensson. 2007. Female sexual polymorphism and fecundity consequences of male mating harassment in the wild. Plos One 2.

Gosden, T. P., and E. I. Svensson. 2009. Density-dependent male mating harassment, female resistance, and male mimicry. American Naturalist 173:709-721.

Grant, P. R. 1994. Ecological character displacement. Science 266:746-746.

Greenfield, M. D. 2002. Signalers and receivers: mechanisms and evolution of arthropod communication. Oxford University Press Oxford.

Guevara-Fiore, P., J. Stapley, J. Krause, I. Ramnarine, and P. Watt. 2010. Male matesearching strategies and female cues: how do male guppies find receptive females?

Animal Behaviour 79:1191-1197.

Guridi, M., B. Soret, L. Alfonso, and A. Arana. 2011. Single nucleotide polymorphisms

in the Melanocortin 1 Receptor gene are linked with lightness of fibre colour in Peruvian alpaca (Vicugna pacos). Animal Genetics 42:679-682.

Gwynne, D. T. 1981. Sexual difference theory: mormon crickets show role reversa in mate choice. Science 213:14.

Hammers, M., and H. Van Gossum. 2008. Variation in female morph frequencies and mating frequencies: random, frequency-dependent harassment or male mimicry? Animal Behaviour 76:1403-1410.

Hampton, K. J., K. A. Hughes, and A. E. Houde. 2009. The allure of the distinctive: reduced sexual responsiveness of female guppies to 'redundant' male colour patterns. Ethology 115:475-481.

Hardling, R., and J. Bergsten. 2006. Nonrandom mating preserves intrasexual polymorphism and stops population differentiation in sexual conflict. American Naturalist 167:401-409.

Heeger, D. 1997. Signal detection theory. Department of Psychology, Stanford University, Stanford, CA, Teaching Handout.

Hill, G. E. 1993. Male mate choice and the evolution of female plumage coloration in the 
house finch. Evolution 47:1515-1525.

Hooper, R. E., S. J. Plaistow, and Y. Tsubaki. 2006. Signal function of wing colour in a polymorphic damselfly, Mnais costalis Selys (Zygoptera : Calopterygidae).

Odonatologica 35:15-22.

Huang, S. C., and J. Reinhard. 2012. Color change from male-mimic to gynomorphic: a new aspect of signaling sexual status in damselflies (Odonata, Zygoptera). Behavioral Ecology 23:1269-1275.

Iserbyt, A., J. Bots, H. Van Gossum, and T. N. Sherratt. 2013. Negative frequencydependent selection or alternative reproductive tactics: maintenance of female polymorphism in natural populations. Bmc Evolutionary Biology 13:10. Iserbyt, A., and H. Van Gossum. 2009. Unexpected absence of behavioural differences between female damselfly colour morphs. Animal Behaviour 78:1463-1469.

Iserbyt, A., and H. Van Gossum. 2011. Show your true colour: cues for male mate preference in an intra-specific mimicry system. Ecological Entomology 36:544-548. Iserbyt, A., J Bots, H. Van Gossum and K. Jordaens. 2010. Did historical events shape current geographic variation in female morph frequencies. Journal of Zoology 282:256265.

Jennions, M. D., and M. Petrie. 1997. Variation in mate choice and mating preferences: a review of causes and consequences. Biological Reviews 72:283-327.

Johnson, C. 1964. Evolution of territoriality in Odonata. Evolution 18:89-92.

Johnstone, R. A., and A. Grafen. 1993. Dishonesty and the handicap principle. Animal Behaviour 46:759-764.

Johnstone, R. A., J. D. Reynolds, and J. C. Deutsch. 1996. Mutual mate choice and sex differences in choosiness. Evolution 50:1382-1391.

Joop, G., A. Mitschke, J. Rolff, and M. T. Siva-Jothy. 2006a. Immune function and parasite resistance in male and polymorphic female Coenagrion puella. Bmc

Evolutionary Biology 6:19.

Joop, G., M. T. Siva-Jothy, and J. Rolff. 2006b. Female colour polymorphism: gender and the eye of the beholder in damselflies. Evolutionary Ecology 20:259-270.

Keranen, I., A. Kahilainen, K. E. Knott, J. S. Kotiaho, and K. Kuitunen. 2013. High maternal species density mediates unidirectional heterospecific matings in Calopteryx damselflies. Biological Journal of the Linnean Society 108:534-545.

Kettlewell, H. B. D. 1955. Recognition of appropriate backgrounds by the pale and black phases of Lepidoptera. Nature 175:943-944.

Kokko, H., R. Brooks, J. M. McNamara, and A. I. Houston. 2002. The sexual selection continuum. Proceedings of the Royal Society B-Biological Sciences 269:1331-1340. Kokko, H., and P. Monaghan. 2001. Predicting the direction of sexual selection. Ecology Letters 4:159-165.

Kuitunen, K., J. S. Kotiaho, M. Luojumaki, and J. Suhonen. 2011. Selection on size and secondary sexual characters of the damselfly Calopteryx splendens when sympatric with the congener Calopteryx virgo. Canadian Journal of Zoology-Revue Canadienne De Zoologie 89:1-9.

Kunte, K. 2009. Female-limited mimetic polymorphism: a review of theories and a critique of sexual selection as balancing selection. Animal Behaviour 78:1029-1036.

Kvarnemo, C., and L. W. Simmons. 1999. Variance in female quality, operational sex ratio and male mate choice in a bushcricket. Behavioral Ecology and Sociobiology 
45:245-252.

Lajeunesse, M. J., and M. R. Forbes. 2003. A comparison of structural size and condition in two female morphs of the damselfly Nehalennia irene (Hagen) (Zygoptera :

Coenagrionidae). Odonatologica 32:281-287.

Lam, E. 2004. Damselflies of the Northeast. Forest Hills, NY: Biodiversity Books.

Majerus, M. E. 2009. Industrial melanism in the peppered moth, Biston betularia: an excellent teaching example of Darwinian evolution in action. Evolution: Education and Outreach 2:63-74.

Martel, V., D. Damiens, and G. Boivin. 2008. Male mate choice in Trichogramma turkestanica. Journal of Insect Behavior 21:63-71.

McPeek, M. A., L. B. Symes, D. M. Zong, and C. L. McPeek. 2011. Species recognition and patterns of population variation in the reproductive structures of a damselfly genus. Evolution 65:419-428.

McTavish, E. J., G. K. Smith, R. F. Guerrero, and E. J. Gering. 2012. Variation in flight morphology in a damselfly with female-limited polymorphism. Evolutionary Ecology Research 14:325-341.

Meyer, R. C., H. Witucka-Wall, M. Becher, A. Blacha, A. Boudichevskaia, P. Dormann, O. Fiehn, S. Friedel, M. von Korff, J. Lisec, M. Melzer, D. Repsilber, R. Schmidt, M. Scholz, J. Selbig, L. Willmitzer, and T. Altmann. 2012. Heterosis manifestation during early Arabidopsis seedling development is characterized by intermediate gene expression and enhanced metabolic activity in the hybrids. Plant Journal 71:669-683.

Miller, M. N., and O. M. Fincke. 1999. Cues for mate recognition and the effect of prior experience on mate recognition in Enallagma damselflies. Journal of Insect Behavior 12:801-814.

Miller, M. N., and O. M. Fincke. 2004. Mistakes in sexual recognition among sympatric Zygoptera vary with time of day and color morphism (Odonata: Coenagrionidae). International Journal of Odonatology 7:471-491. Mullen, S. P., and J. A. Andres. 2007. Rapid evolution of sexual signals in sympatric Calopteryx damselflies: reinforcement or 'noisy-neighbour' ecological character displacement? Journal of Evolutionary Biology 20:1637-1648.

Nakahashi, W. 2008. Quantitative genetic models of sexual selection by male choice. Theoretical population biology 74:167-181.

Nijhout, F. H. 2010. Molecular and physiological basis of color pattern formation. In Advances in insect physiology:insect integument and color volume 38. Casas, J and S. J. Simpson (ed). Academic Press. Elsevier Ltd.

Olberg, R. A. 1981. Object- and self-movement detectors in the ventral nerve cord of the dragonfly. Journal of Comparative Physiology 141:327-334.

Olberg, R. A., A. Worthington, and K. Venator. 2000. Prey pursuit and interception in dragonflies. Journal of Comparative Physiology A 186:155-162.

Outomuro, D., and F. J. Ocharan. 2011. Wing pigmentation in Calopteryx damselflies: a role in thermoregulation? Biological Journal of the Linnean Society. 103:36-44.

Paemelaere, E. A. D., C. Guyer, and F. S. Dobson. 2011. A phylogenetic framework for the evolution of female polymorphism in anoles. Biological Journal of the Linnean Society 104:303-317.

Parker, G. 1974. Courtship persistence and female-guarding as male time investment strategies. Behaviour 48:157-184. 
Parker, G. 1983. Mate quality and mating decisions. Mate choice. Cambridge University Press pg 141-161.

Parris, M. J. 1999. Hybridization in leopard frogs (Rana pipiens complex): Larval fitness components in single-genotype populations and mixtures. Evolution 53:1872-1883. Parris, M. J. 2001. High larval performance of leopard frog hybrids: Effects of environment-dependent selection. Ecology 82:3001-3009.

Penney, H. D., C. Hassall, J. H. Skevington, K. R. Abbott, and T. N. Sherratt. 2012. A comparative analysis of the evolution of imperfect mimicry. Nature 483:461-U110. Prum, R. O., J .A. Cole, and R. H. Torres. 2004. Blue integumentary structural colours in dragonflies (Odonata) are not produced by incoherent Tyndall scattering. Journal of Experimental Biology 207:3999-4009.

Pryke, S., L. Astheimer, S. Griffith, and W. Buttemer. 2012. Covariation in life-history traits: Differential effects of diet on condition, hormones, behavior, and reproduction in genetic finch morphs. American Naturalist 179 375-390.

R Core Development Team. 2013. R: A language and environment for statistical computing. R Foundation for Statistical Computing, Vienna.

Reading, K. L., and P. R. Backwell. 2007. Can beggars be choosers? Male mate choice in a fiddler crab. Animal Behaviour 74:867-872.

Rivera, A. C., and J. Andrés. 2002. Male coercion and convenience polyandry in a calopterygid damselfly. Journal of Insect Science 2:14.

Rivera, A. C., and R. A. Sanchez-Guillen. 2007. Male-like females of a damselfly are not preferred by males even if they are the majority morph. Animal Behaviour 74:247-252. Robertson, H. M. 1985. Female dimorphism and mating-behavior in a damselfly, Ischnura ramburi - females mimicking males. Animal Behaviour 33:805-809.

Rosin, Z. M., P. Olborska, A. Surmacki, and P. Tryjanowski. 2011. Differences in predatory pressure on terrestrial snails by birds and mammals. Journal of Biosciences 36:691-699.

Saether, S. A., P. Fiske, and J. A. Kalas. 2001. Male mate choice, sexual conflict and strategic allocation of copulations in a lekking bird. Proceedings of the Royal Society BBiological Sciences 268:2097-2102.

Sanchez-Guillen, R. A., S. M. J. Martinez-Zamilpa, J. G. Jimenez-Cortes, M. R. L. Forbes, and A. Cordoba-Aguilar. 2013. Maintenance of polymorphic females: do parasites play a role? Oecologia 171:105-113.

Sanchez-Guillen, R. A., H. Van Gossum, and A. C. Rivera. 2005. Hybridization and the inheritance of female colour polymorphism in two ischnurid damselflies (Odonata :

Coenagrionidae). Biological Journal of the Linnean Society 85:471-481.

Schluter, D., and J. D. McPhail. 1992. Ecological character displacement and speciation in sticklebacks. American Naturalist 140:85-108.

Schultz, T. D., C. N. Anderson, and L. B. Symes. 2008. The conspicuousness of colour cues in male pond damselflies depends on ambient light and visual system. Animal Behaviour 76:1357-1364.

Servedio, M. R., and R. Lande. 2006. Population genetic models of male and mutual mate choice. Evolution 60:674-685.

Sherratt, T. N. 2001. The evolution of female-limited polymorphisms in damselflies: a signal detection model. Ecology Letters 4:22-29.

Sherratt, T. N. 2013. Personal communication. 
Sherratt, T. N., and M. R. Forbes. 2001. Sexual differences in coloration of Coenagrionid damselflies (Odonata): a case of intraspecific aposematism? Animal Behaviour 62:653660.

Sherratt, T. N., and D. M. Wilkinson. 2009. Big questions in ecology and evolution. Oxford University Press. Oxford.

Shuster, S. M., and M. J. Wade. 2003. Mating systems and strategies. Princeton University Press.

Sinervo, B., and C. M. Lively. 1996. The rock-paper-scissors game and the evolution of alternative male strategies. Nature 380:240-243.

Sinervo, B., E. Svensson, and T. Comendant. 2000. Density cycles and an offspring quantity and quality game driven by natural selection. Nature 406:985-988.

Singer, F. 1990. Reproductive costs arising from incomplete habitat segregation among 3 species of Leucorrhina dragonflies. Behaviour 115:188-202.

Sirot, L. K., and H. J. Brockmann. 2001. Costs of sexual interactions to females in Rambur's forktail damselfly, Ischnura ramburi (Zygoptera : Coenagrionidae). Animal Behaviour 61:415-424.

Sirot, L. K., H. J. Brockmann, C. Marinis, and G. Muschett. 2003. Maintenance of a female-limited polymorphism in Ischnura ramburi (Zygoptera : Coenagrionidae). Animal Behaviour 66:763-775.

Smith, J. M. 1989. Evolutionary genetics. Oxford University Press.

Stoks, R. 1998. Effect of lamellae autotomy on survival and foraging success of the damselfly Lestes sponsa (Odonata: Lestidae). Oecologia 117:443-448.

Svensson, B. G. 1997. Swarming behavior, sexual dimorphism, and female reproductive status in the sex role-reversed dance fly species Rhamphomyia marginata. Journal of Insect Behavior 10:783-804.

Svensson, B. G., and E. Petersson. 1987. Sex-role reversed courtship behavior, sexual dimorphism and nuptial gifts in the dance fly, Empis borealis (1). Annales Zoologici Fennici 24:323-334.

Svensson, E. I., J. Abbott, and R. Hardling. 2005. Female polymorphism, frequency dependence, and rapid evolutionary dynamics in natural populations. American Naturalist 165:567-576.

Svensson, E. I., J. K. Abbott, T. P. Gosden, and A. Coreau. 2009. Female polymorphisms, sexual conflict and limits to speciation processes in animals.

Evolutionary Ecology 23:93-108.

Swanson-Wagner, R. A., Y. Jia, R. DeCook, L. A. Borsuk, D. Nettleton, and P. S. Schnable. 2006. All possible modes of gene action are observed in a global comparison of gene expression in a maize F-1 hybrid and its inbred parents. Proceedings of the National Academy of Sciences of the United States of America 103:6805-6810. Szykman, M., A. L. Engh, R. C. Van Horn, S. M. Funk, K. T. Scribner, and K. E. Holekamp. 2001. Association patterns among male and female spotted hyenas (Crocuta crocuta) reflect male mate choice. Behavioral Ecology and Sociobiology 50:231-238. Takahashi, Y., G. Morimoto, and M. Watanabe. 2012. Ontogenetic colour change in females as a function of antiharassment strategy. Animal Behaviour 84:685-692. Takahashi, Y., and M. Watanabe. 2009. Diurnal changes and frequency dependence in male mating preference for female morphs in the damselfly Ischnura senegalensis (Rambur) (Odonata: Coenagrionidae). Entomological Science 12:219-226. 
Takahashi, Y., and M. Watanabe. 2010a. Female reproductive success is affected by selective male harassment in the damselfly by Ischnura senegalensis. Animal Behaviour 79:211-216.

Takahashi, Y., and M. Watanabe. 2010b. Morph-specific fecundity and egg size in the female-dimorphic damselfly Ischnura senegalensis. Zoological Science 27:325-329. Ting, J. J., J. Bots, F. P. Jvostov, H. Van Gossum, and T. N. Sherratt. 2009. Effects of extreme variation in female morph frequencies on the mating behaviour of male damselflies. Behavioral Ecology and Sociobiology 64:225-236.

Tynkkynen, K., A. Grapputo, J. S. Kotiaho, M. J. Rantala, S. Vaananen, and J. Suhonen. 2008. Hybridization in Calopteryx damselflies: the role of males. Animal Behaviour 75:1431-1439.

Tynkkynen, K., M. J. Rantala, and J. Suhonen. 2004. Interspecific aggression and character displacement in the damselfly Calopteryx splendens. Journal of Evolutionary Biology 17:759-767.

Ubukata, H. 1984. Ecological studies of Cordulia aenea amurensis selys .7. oviposition site selection and avoidance of additional mating by females of the dragonfly, Cordulia aenea amurensis Selys (Corduliidae). Researches on Population Ecology 26:285-301. Uesugi, K. 1996. The adaptive significance of batesian mimicry in the swallowtail butterfly, Papilio polytes (Insecta, Papilionidae): associative learning in a predator. Ethology 102:762-775.

Uhia, E., and A. C. Rivera. 2005. Male damselflies detect female mating status: importance for postcopulatory sexual selection. Animal Behaviour 69:797-804. Van Gossum, H., J. Bots, J. Van Heusden, M. Hammers, K. Huyghe, and N. I. Morehouse. 2011. Reflectance spectra and mating patterns support intraspecific mimicry in the colour polymorphic damselfly Ischnura elegans. Evolutionary Ecology 25:139154.

Van Gossum, H., L. De Bruyn, and R. Stoks. 2005a. Reversible switches between malemale and male-female mating behaviour by male damselflies. Biology Letters 1:268-270. Van Gossum, H., M. Forbes, and T. N. Sherratt. 2007. Reproductive interference between Nehalennia damselfly species. Ecoscience 14:1-7.

Van Gossum, H., T. Robb, M. R. Forbes, and L. Rasmussen. 2008. Female-limited polymorphism in a widespread damselfly: morph frequencies, male density, and phenotypic similarity of andromorphs to males. Canadian Journal of Zoology-Revue Canadienne De Zoologie 86:1131-1138.

Van Gossum, H., R. Stoks, and L. De Bruyn. 2001a. Frequency-dependent male mate harassment and intra-specific variation in its avoidance by females of the damselfly Ischnura elegans. Behavioral Ecology and Sociobiology 51:69-75.

Van Gossum, H., R. Stoks, and L. De Bruyn. 2001b. Reversible frequency-dependent switches in male mate choice. Proceedings of the Royal Society B-Biological Sciences 268:83-85.

Van Gossum, H., R. Stoks, and L. De Bruyn. 2005b. Lifetime fitness components in female colour morphs of a damselfly: density- or frequency-dependent selection? Biological Journal of the Linnean Society 86:515-523.

Van Gossum, H., R. Stoks, E. Matthysen, F. Valck, and L. De Bruyn. 1999. Male choice for female colour morphs in Ischnura elegans (Odonata, Coenagrionidae): testing the hypotheses. Animal Behaviour 57:1229-1232. 
Van Gossum, H. R. S., L De Bruyn. 2004. Conspicious body colouration and predation risk in damselflies are andromorphs easier to detect than gynomorphs? Belgian Journal of Zoology 134:37-40.

Vernon, J. E. N., A. F. O. O'Farrell, and Dixon, B. 1974. The fine structure of Odonata chromatophores. Tissue Cell 6:613 -626.

Vincent, A., I. Ahnesjö, A. Berglund, and G. Rosenqvist. 1992. Pipefishes and seahorses: are they all sex role reversed? Trends in Ecology \& Evolution 7:237-241.

Waage, J. K. 1975a. Reproductive isolation and potential for character displacement in damselflies, Calopteryx maculata and Calopteryx aequabilis (Odonata-calopterygidae). Systematic Zoology 24:24-36.

Waage, J. K. 1979. Reproductive character displacement in Calopteryx (Odonata, Calopterygidae). Evolution 33:104-116.

Waage, J. K. 1987. Choice and utilization of oviposition sites by female Calopteryxmaculata (Odonata, Calopterygidae) .1. Influence of site size and the presence of other females. Behavioral Ecology and Sociobiology 20:439-446.

Walguarnery, J. W., M. A. Butler, and R. Shroeder. 2009. Visual target detection in damselflies. DTIC Document.

Watanabe, M., and M. Taguchi. 1990. Mating tactics and male wing dimorphism in the damselfly, Mnais-pruinosa-costalis selys (Odonata, Calopterygidae). Journal of Ethology 8:129-137.

Watts, P.C., J. R. Rouquette, I. J. Saccheri, S. J. Kemp, and D. J. Thompson. 2004.

Molecular and ecological evidence for small-scale isolation by distance in an endangered damselfly, Coenagrion mercuriale. Molecular Ecology 13:293-2945.

Wong, B. B. M. 2004. Male competition is disruptive to courtship in the Pacific blue-eye. Journal of Fish Biology 65:333-341.

Yamauchi, A. 1993. A population-dynamic model of Batesian mimicry. Researches on Population Ecology 35:295-315.

Yang, E.-C., and D. Osorio. 1991. Spectral sensitivities of photoreceptors and lamina monopolar cells in the dragonfly, Hemicordulia tau. Journal of Comparative Physiology A 169:663-669.

Zeiss, C., A. Martens, and J. Rolff. 1999. Male mate guarding increases females' predation risk? A case study on tandem oviposition in the damselfly Coenagrion puella (Insecta : Odonata). Canadian Journal of Zoology-Revue Canadienne De Zoologie 77:1013-1016. 